\title{
Crimes nos Municípios do Rio Grande do Sul: Análise a partir de um Î́ndice Geral de Criminalidade
}

\author{
Renan Xavier Cortes ${ }^{1}$ \\ Adelar Fochezatto ${ }^{2}$ \\ Paulo de Andrade Jacinto ${ }^{3}$
}

\section{Resumo}

A Economia do Crime dedica-se ao estudo da atividade humana considerada ilegal e sua mensuração de maneira apropriada, o que constitui um grande desafio na literatura. Este artigo propõe uma metodologia de mensuração da atividade criminal nos municípios do Rio Grande do Sul combinando diversos tipos de ocorrências criminais em uma série histórica de 2002 até 2015. Fazendo uso de um refinado modelo espaço-temporal Bayesiano, com a metodologia Integrated Nested Laplace Approximation, os resultados encontrados buscam mensurar a criminalidade geral contornando problemas de estimações como alta volatilidade e raridade de ocorrências em localidades pouco habitadas. Ademais, os índices construídos contemplam a gravidade específica de cada crime e representam uma interpretabilidade simples.

\section{Palavras-Chave}

Economia do Crime. Índice de Criminalidade Municipal. Econometria Espaço-Temporal. Inferência Bayesiana. INLA.

\footnotetext{
Abstract

The Economics of Crime is dedicated to study illegal human activity and measuring it properly is a major challenge in the literature. This article proposes a methodology for measuring criminal activity in the municipalities of Rio Grande do Sul combining several types of criminal occurrences in a historical series ranging from 2002 to 2015. Using a refined Bayesian space-time model with the Integrated Nested Laplace Approximation approach, the results measure general criminal activity avoiding problems of estimates such as high volatility and rarity of occurrences in low population cities. In addition, the proposed indexes contemplate the severity of each crime and represent a simple interpretability.

1 Doutor em Economia - Pontifícia Universidade Católica do Rio Grande do Sul (PUCRS)

Endereço: Av. Ipiranga, 6681, Prédio 50 - Partenon - Porto Alegre/RS - Brasil - CEP: 90619-900

E-mail: renanxcortes@gmail.com - https://orcid.org/0000-0002-1889-5282

2 Professor - Pontifícia Universidade Católica do Rio Grande do Sul (PUCRS)

Endereço: Av. Ipiranga, 6681, Prédio 50/1105 - Partenon - Porto Alegre/RS - Brasil

CEP: 90619-900 - E-mail: adelar@pucrs.br - https://orcid.org/0000-0001-7192-3986

3 Professor - Universidade Federal do Paraná (UFPR)

Endereço: Av. Prefeito Lothário Meissner, 632 - Jardim Botânico - Curitiba/PR - Brasil

CEP: 80210-170 - E-mail: paulo.jacinto@ufpr.br - https://orcid.org/0000-0002-8563-9190

Recebido: 20/09/2017. Aceite: 23/02/2018.
}

(c) (i) (8) Esta obra está licenciada com uma Licença Creative Commons Atribuição-Não Comercial 4.0 Internacional. 


\section{Keywords}

Economics of Crime. Municipal Crime Rate. Spatio-Temporal Econometrics. Bayesian Inference. INLA.

\section{JEL Classification}

C11. C23. K42.

\section{Introdução}

Segundo os registros de boletins de ocorrência da Secretaria de Segurança Pública do Rio Grande do Sul e estimativas populacionais da Fundação de Economia e Estatística, no estado do Rio Grande do Sul, entre 2002 e 2015, aumentou o número de homicídios dolosos em $53,7 \%$, de latrocínios em $28,4 \%$, de roubos em $47,1 \%$, de roubos de veículos em $116,5 \%$ e de furtos de veículos em $8,7 \%$, enquanto que a população cresceu $7,5 \%$. Conforme Monteiro (2009) e Cortes (2016), a maior parte das taxas criminais de ocorrência é concentrada em municípios mais populosos, em especial, na região metropolitana de Porto Alegre e em municípios litorâneos. No entanto, estes rankings municipais de criminalidade podem variar substancialmente dependendo do tipo de crime que se está analisando e, além disso, a queda do bem-estar da potencial vítima ou o "efeito trauma" da vítima também varia de acordo com a gravidade da atividade criminosa. Por exemplo, é razoável supor que uma pessoa que teve seu carro furtado experienciou um evento menos traumático do que uma vítima que teve seu carro roubado. ${ }^{1}$

Quando se trabalha com indicadores de criminalidade, conforme Khan (2005), Justus e Kassouf (2008) e Cerqueira D., Lobão e Carvalho (2005), alguns pontos devem ser considerados. Khan (2005) analisa estes pontos argumentando que os dados oficiais de criminalidade estão sujeitos a uma série de limites de validade e confiabilidade, pois são antes um retrato do processo social de notificação de crimes do que um retrato fiel do universo dos crimes realmente cometidos num determinado local, uma vez que para um crime ir para as estatísticas oficiais ele deve ser detectado, notificado e registrado. Algumas das especificidades a serem levantadas é a sazona-

1 O furto se caracteriza como a subtração do bem sem o contato direto com a vítima, enquanto que o roubo é caracterizado como um crime mais grave, pois o delinquente coage a vítima a entregar o bem mediante ameaça ou emprego de violência. 
lidade criminal, a subnotificação, ${ }^{2}$ a concentração em pequenos locais, a propensão da vítima a notificar o crime (que pode variar de acordo com a percepção com relação ao sistema policial, tipo de crime ou bem roubado) e a simultaneidade entre ação policial e notificação.

Um dos problemas mais conhecidos na literatura sobre o tema é como fazer uma boa estimação do número de ocorrências criminais em municípios pequenos. Este problema advém, basicamente, por dois fatores: a alta volatilidade que um município pequeno pode apresentar nas suas taxas brutas de criminalidade e a alta probabilidade de não se observar algum evento em um dado período de tempo. Com relação à primeira questão, pode-se pensar que é possível que um evento atípico em um determinado município pouco populoso aumente severamente as taxas criminais que, usualmente, são apresentadas em termos de 100.000 habitantes. Carvalho A., Marques da Silva, Junior e Albuquerque (2012) verificaram que em 2008 a taxa de homicídio de Nova Marilândia (MT) foi de 211,1 o que representa um valor mais de três vezes maior do que a do país com maior taxa de homicídio do mundo. ${ }^{3}$ No entanto, este município apresentou apenas cinco homicídios tendo apenas 2.369 habitantes.

Com relação à segunda questão, a sua pertinência se deve ao fato de que mesmo em uma cidade que não teve nenhum caso de crime em determinado ano, não necessariamente a probabilidade de ele acontecer seja nula, pois, na realidade, não foi observada uma janela de tempo suficiente para ele acontecer. Este fenômeno, que também abrange o campo epidemiológico, já possui uma ampla discussão e difusão na literatura, podendo-se citar Catelan, Lagazio e Biggeri (2010), Clayton e Kaldor (1987), Marshall (1991) e Pringle (1996).

A maior parte das metodologias tenta remediar o problema estabelecendo estimativas bayesianas que podem levar em consideração a estrutura espacial para suavizar as estimativas brutas. Carvalho, A., Marques da Silva, Junior e Albuquerque (2012) analisam diferentes métodos de estimação para taxas de homicídio para os municípios brasileiros comparando taxas brutas, espaciais, bayesianas empíricas, bayesianas empíricas espaciais e a taxa bayesiana de Clayton e Kaldor (1987). Tendo em vista o escopo nacional do trabalho não é aconselhada a aplicação da taxa bayesiana em-

2 Khan (2005) mostra que Pesquisas de Vitimização sugerem que, em média, apenas um terço dos crimes são notificados.

3 Segundo Waiselfisz (2014), o país que apresentou a maior taxa, em 2009, foi El Salvador com 62,4 homicídios por 100.000 habitantes. 
pírica, pois a correção foi feita com base na média do país. As melhores taxas que se adaptaram foram as bayesianas empíricas, empírica espacial e a de Clayton e Kaldor (1987) com a ressalva da alta sensibilidade frente às distribuições $a$ priori.

Além destas questões que envolvem a qualidade dos registros criminais e problemas de estimação, é preciso também levantar outros pontos pertinentes para se criar um índice geral que combine diferentes tipos de crime. Neste sentido, Freitas, Cadaval e Gonçalves (2016) propuseram um índice geral de criminalidade para os municípios gaúchos, fazendo uso da estimação empírica bayesiana de acordo com a similaridade dos municípios e combinando os crimes ponderando-os de acordo com a pena prevista no Código Penal Brasileiro para o ano de 2013. O método Bayesiano empírico representa uma combinação entre a taxa bruta uma estimativa global. Neste trabalho, ocorrências de 14 crimes disponibilizados pela SSP-RS foram analisadas e combinadas. Uma limitação deste estudo foi não discernir de maneira satisfatória os municípios gaúchos com população pequena, o que pode ter comprometido o resultado final do índice e o seu uso não evidenciar a real situação do município. No âmbito do Rio Grande do Sul, Cortes (2016) fez uso de técnicas estatísticas multivariadas combinando componentes principais e análise fatorial a fim de encontrar uma combinação linear satisfatória de 14 crimes para o ano de 2014 para a criação de um índice municipal sem levar em consideração a gravidade penal. Algo similar foi feito também por Monteiro (2009), enquanto que a gravidade penal também foi utilizada em Saraiva, Conceição e França (2016).

A criminologia aponta que o fenômeno criminal é multifatorial, podendo indicar que as circunstâncias físicas, janelas de oportunidades, espaços defensivos e componentes geográficos podem ser determinantes (Shaw Clifford, Mckay (1942), Beato, Claudio, (1998)). Neste contexto, é razoável supor que o fenômeno criminal é afetado por um componente espacial, tendo em vista que municípios podem afetar municípios próximos. Sendo assim, esse componente pode desempenhar um papel importante na correção das estimativas (Carvalho, A., Marques Da Silva, Junior, Albuquerque 2012). O método Bayesiano de suavizamento espacial faz uso da abordagem Integrated Nested Laplace Approximation (INLA), que é uma recente abordagem de estimação Bayesiana para uma ampla classe de modelos. Introduzida por Rue, Martino e Chopin (2009), esta metodologia se destaca perante as abordagens usuais de inferência Bayesiana, tendo em vista que ela permite obter de maneira rápida as estimativas das distribuições marginais a posteriori, sem necessitar de simulações estocásticas tais como 
os métodos MCMC (Gelfand, Smith 1990) ou Gibbs Sampling (Geman, Geman 1984), pois ela trabalha com aproximações analíticas destas distribuições. Além disso, conforme Cortes (2014), devido a sua natureza de aproximação analítica, o INLA não sofre dos conhecidos problemas de convergência dos métodos MCMC discutidos, por exemplo, em Gelman e Rubin (1992), Raftery e Lewis (1992) e Gamerman e Lopes (2006).

A partir dessas considerações, o presente trabalho tem como objetivo propor um índice de criminalidade municipal do Rio Grande do Sul, o ICrimeRS, para englobar diferentes características e tentar evitar possíveis problemas de estimação. As contribuições deste trabalho podem ser vistas em duas direções. Na primeira, relacionada à metodologia de construção do indicador, permite fácil interpretabilidade, possibilitando inclusive desagregar o seu valor em diferentes classes de crimes. Na segunda, os componentes espaciais são levados em consideração, a fim de mitigar o efeito de especificidade regional.

Além desta breve introdução, o artigo está dividido em quatro seções. A próxima seção apresenta a metodologia. A seção três descreve a fonte de dados utilizada e uma breve descrição das estatísticas descritivas. A quarta seção apresenta os resultados e, por fim, a última traz as considerações finais.

\section{Metodologia}

Esta seção apresenta a metodologia utilizada na construção do índice de criminalidade. Para tanto, inicialmente é definida a medida usada para estimar a taxa de criminalidade. Na sequência, são descritas as matrizes de vizinhanças, os modelos autoregressivos condicionais, a abordagem INLA, os modelos estimados, a agregação do índice e as suas vantagens e desvantagens.

Uma das opções de se estimar a prevalência de uma atividade criminosa pode ser dada pela Taxa Bruta (TB), por 100.000 habitantes, de ocorrência dada pela seguinte equação:

$$
T B_{i}=\frac{Y_{i}}{P_{i}} \times 100.000, i=1, \ldots, n
$$


onde $Y_{i}$ representa o número de casos observados da região $i, P_{i}$ representa a população da região i e o número de unidades geográficas sob estudo. No entanto, conforme já discutido, este tipo de abordagem sofre de diversos problemas tanto em termos de subestimação, quanto em termos de variabilidade, principalmente em unidades geográficas pouco populosas. Uma das opções para evitar este tipo de problema é utilizar a taxa bayesiana empírica proposta por Marshall (1991), utilizada também por Carvalho, Silva e Albuquerque (2012) e em Cerqueira et al. (2013). Essa taxa considera a variável Yi como seguindo uma distribuição de Poisson com parâmetro $\mathrm{P}_{\mathrm{i}} \times \lambda_{\mathrm{i}}$, ou seja, $\mathrm{Y}_{\mathrm{i}} \mid \mathrm{P}_{\mathrm{i}}, \lambda_{\mathrm{i}} \sim \operatorname{Poisson}\left(\mathrm{P}_{\mathrm{i}} \times \lambda_{\mathrm{i}}\right)$. No entanto, em Marshall (1991) a estimativa de $\lambda_{i}$ é muito simples representando apenas uma espécie de média ponderada entre a taxa bruta e a taxa global de eventos de toda a região em estudo da seguinte forma:

$$
\widehat{\lambda}_{l}=w_{i} \times T B_{i}+\left(1-w_{i}\right) \times m
$$

em que $T B_{i}$ é a taxa bruta da região $i, m$ é a taxa global dos eventos (por exemplo, a taxa global do Rio Grande do Sul) e $w_{i}$ é um peso que é diretamente relacionado com o tamanho da população da área $i$. Sendo assim, se o município tem grande população, mais a taxa bruta se aproxima da bayesiana empírica. O nome empírica vem do fato que a distribuição $a$ priori do parâmetro desconhecido $\lambda_{i}$ é estimada diretamente fazendo uso dos dados sob análise.

Os métodos empregados aqui se diferem uma vez que as abordagens farão uso da estrutura espacial de cada uma das unidades observacionais, bem como investigará diferentes estruturas de especificações, estimando os métodos tanto de maneira frequentista, quanto de maneira bayesiana. ${ }^{4}$

\subsection{Matrizes de Vizinhança}

Modelos econométricos espaciais levam em consideração a relação da vizinhança entre as observações. Dados em séries temporais também possuem uma estrutura estabelecida de relacionamento, uma vez que os

4 Uma boa literatura sobre o tema de estatística e econometria espacial pode ser encontrada em Banerjee, Carlin e Gelfand (2004), Besag (1974), Bivand, Pebesma e Gómez-Rubio (2008), LeSage (1997) e LeSage (1999). 
dados podem ser ordenados. No entanto, para dados espaciais não faz sentido uma ordenação, mas sim a definição de uma estrutura de relacionamento associada aos dados que indique a vizinhança de cada uma das unidades geográficas.

A estrutura de vizinhança pode ser representada por uma matriz de adjacência $\mathbf{A}$, associada, que é uma matriz cujo elemento $\mathbf{A}_{\mathrm{i}, \mathrm{e}}$ é 1 se a área $i$ é vizinha da área $j$ e 0 , caso contrário. A matriz $\mathrm{A}$, que também pode ser referida como grafo estruturado, é simétrica e possui zeros na sua diagonal principal, ou seja, $\mathrm{A}_{\mathrm{i}, \mathrm{j}}=0, i=1, \ldots, \mathrm{n}$.

Com relação às estruturas de vizinhança utilizadas, diferentes maneiras podem ser estabelecidas. Uma delas é por vizinhos de contiguidade, mas uma especificação diferente pode ser por vizinhos mais próximos através da distância dos centróides de cada uma das suas localizações. Esta especificação é chamada de vizinho mais próximo de k-ésima ordem ou k-NN (do inglês, $k$ nearest neighbor) e, neste artigo, testou-se até o vizinho mais próximo de terceira ordem conforme a Figura 2.1. ${ }^{5}$

(a)

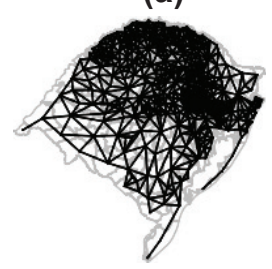

(c)

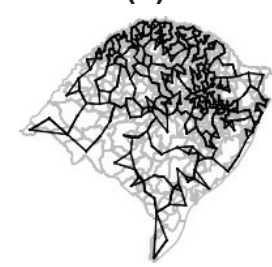

(b)

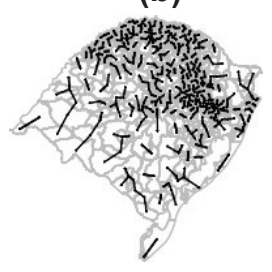

(d)

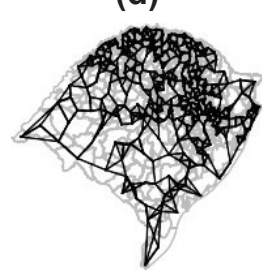

Figura 2.1 - Exemplo de Diferentes Especificações. (a) Vizinhos de contiguidade de $1^{a}$ ordem. (b) k-NN de $1^{\mathrm{a}}$ ordem. (c) k-NN de $2^{\mathrm{a}}$ ordem. (d) k-NN de $3^{\mathrm{a}}$ ordem.

5 Para informações sobre estruturas de matrizes de vizinhança em econometria espacial, recomenda-se o Capítulo 9 de Bivand, Pebesma e Gómez-Rubio (2008). 


\subsection{Modelos Autoregressivos Condicionais}

Nos modelos aqui analisados, a variável de interesse representa o número de ocorrências que aconteceram em determinado ano, de um determinado crime e município. Como esta variável se trata da contagem de frequências de um processo pontual em um espaço contínuo (área do município) a distribuição de probabilidade mais apropriada para descrevê-la é do tipo Poisson (Cerqueira et al. 2013). Sendo assim, os modelos possuem a verossimilhança:

$$
y_{i} \mid \lambda_{i} \sim \operatorname{Poisson}\left(\lambda_{i}\right)
$$

onde a média $\lambda_{i}$ é definida em termos da taxa de risco $\rho_{i}$ e o número esperado de ocorrências $E_{i}$ onde $\lambda_{i}=\rho_{i} \times E_{i}$. Neste caso, o preditor linear pode adquirir a seguinte forma:

$$
\eta_{i}=\log \left(\rho_{i}\right)=\alpha+u_{i}
$$

onde o efeito aleatório $u_{i}$ segue uma especificação estruturada segundo modelos autoregressivos condicionais (CAR, do inglês conditional autoregressive models). Esse efeito introduz a suavização espacial e minimiza os problemas de estimação em populações pequenas, tendo em vista que seu valor depende condicionalmente do efeito dos seus vizinhos.

O modelo CAR é uma proposta de Besag (1974) de uma estrutura condicional para os dados. Considerando $n$ áreas de uma variável aleatória $\boldsymbol{x}=\left(x_{1}, \ldots, x_{n}\right)$, cada uma caracterizada por um grupo de vizinhos $N_{i}$, assume-se que $x_{i}$ segue a seguinte distribuição:

$$
x_{i} \mid \mathbf{x}_{-i} \sim \text { Normal }\left(\mu_{i}+\sum_{j=1}^{n} r_{i j}\left(x_{j}-\mu_{j}\right), s_{i}^{2}\right)
$$

onde $\mu_{j}$ é a média da área $j$ e $s_{i}^{2}=\sigma_{x}^{2} / N_{i}$ é a variância da área $i$, que depende do número de vizinhos $N_{i}=\# N_{(i)}$ o que faz com que à medida que $\mathrm{o}$ número de vizinhos da área $i$ aumente, sua variância diminua. Esta estrutura de variância estabelece que na presença de alta correlação espacial, quanto mais vizinhos uma área tiver, mais informação terá para estimar o seu efeito aleatório, enquanto que o parâmetro de variância $\sigma_{x}^{2}$ controla a variação dos efeitos aleatórios estruturados espacialmente. A quantidade $r_{i j}$ indica 
a proximidade espacial e é calculada como $\phi \times W_{i j}$, onde $W_{i j}=a_{i j} / N_{i}, a_{i j}$ é 1 se as áreas $i$ e $j$ são vizinhas e 0 caso contrário, enquanto que o parâmetro $\phi$ controla a adequação da distribuição.

Um modelo alternativo também foi proposto por Besag, York e Mollie (1991) onde um termo não estruturado é incluído no preditor linear da seguinte forma:

$$
\eta_{i}=\log \left(\rho_{i}\right)=\alpha+u_{i}+\varepsilon_{i}
$$

onde $u_{i}$ o efeito aleatório também segue uma especificação estruturada CAR, descrita anteriormente, e o termo $\varepsilon_{i}$ segue um termo não estruturado $\varepsilon_{i} \sim \operatorname{Normal}\left(0, \sigma_{\varepsilon}^{2}\right)$. Este modelo é denominado CAR intrínseco ou BYM, de Besag-York-Mollie. Um dos motivos para se estimar os modelos BYM é evitar um possível suavizamento excessivo, já que neste modelo há um efeito aleatório não espacial para controlar esse efeito.

\subsection{Integrated Nested Laplace Approximation}

A classe de modelos que a metodologia INLA trabalha é denominada modelos Gaussianos Latentes onde a variável dependente $y_{i}$ é assumida pertencer a uma família de distribuições onde a sua média $\mu_{i}$ é conectada a um preditor linear aditivo $\eta_{i}$ através de uma função de ligação $g\left(\mu_{i}\right)=\eta_{i}$ tal que

$$
\eta_{i}=\alpha+\sum_{j=1}^{n_{f}} f^{(j)}\left(u_{j i}\right)+\sum_{k=1}^{\eta_{\beta}} \beta_{k} z_{k i}
$$

onde $\left\{f^{(j)}(\cdot)\right\}$ 's são funções desconhecidas das covariáveis $\boldsymbol{u}$ e os $\left\{\beta_{k}\right\}$ 's representam o efeito linear das covariáveis $\boldsymbol{z}$. Observe que, nesta representação, as covariáveis $\boldsymbol{Z}$ representam um caso particular das funções desconhecidas das covariáveis $\boldsymbol{u}$. Neste modelo, todas as variáveis latentes, isto é, $\alpha,\left\{f^{(j)}(\cdot)\right\}$ e $\left\{\beta_{k}\right\}$ são assumidas Gaussianas a priori. Em modelos espaciais, a dependência pode ser modelada usando a covariável espacial $\boldsymbol{u}$ como sendo $f^{(j)}\left(u_{s}\right)=f_{s}^{(j)}$ onde representa a locação espacial ou região.

Esta classe de modelos também pode ser escrita como uma classe de modelos hierárquicos Bayesianos em três estágios: a verossimilhança, o campo latente e a priori dos hiperparâmetros. Se assumirmos uma estrutura de 
dependência condicional para as variáveis do campo latente, este vetor é um Gaussian Markov Random Fields (GMRFs). O INLA explora a esparsidade da matriz de covariâncias do GMRFs fazendo diversas aproximações analíticas.

Para maiores informações e aplicações de metodologia, incluindo para dados de homicídios e processos espaciais econômicos usando dados brasileiros, ver Rue, Martino e Chopin (2009), Martino e Rue (2009), Martins et al. (2012), Ruiz-Cárdenas, Krainski e Rue (2011), Blangiardo et al. (2013), Cortes (2014), Laurini (2016) e Laurini (2017).

\subsection{Modelos}

A fim de estimar de uma maneira mais otimizada as frequências de ocorrências criminais, os modelos utilizados seguem variações das abordagens descritas anteriormente. A ideia foi combinar modelos mais parcimoniosos (isto é, com menor número de parâmetros) com modelos mais sofisticados que englobam tanto termos estruturados, não estruturados e efeitos aleatórios temporais. Neste contexto, o conceito de estruturado significa que o efeito segue uma estrutura de dependência condicional do tipo CAR. O efeito estruturado de município pode ser entendido como um efeito fixo de município no sentido mais tradicional de painel. Além disso, o modelo de tendência estocástica escolhido (random walk) representa uma decomposição de componente permanente e transitório usual em economia. O efeito do intercepto mais o componente random walk capturam a tendência temporal de cada crime no modelo.

Em suma, testamos quatro tipos de modelos: i) modelo somente com efeito aleatório estruturado de município (Equação 7); ii) modelo com efeito aleatório estruturado de município mais efeito aleatório não estruturado (Equação 8); iii) modelo com efeito aleatório estruturado de município com componente temporal do tipo passeio aleatório (random walk) de primeira ordem (Equação 9); e o modelo mais complexo, iv) modelo com efeito aleatório estruturado de município mais efeito aleatório não estruturado com componente temporal do tipo passeio aleatório (random walk) de primeira ordem (Equação 10). 
Todas as abordagens foram estimadas para todos os tipos de estruturas de vizinhança fazendo da abordagem INLA.

Modelo Besag/CAR:

$$
\begin{array}{ll}
y_{i} \mid \lambda_{i} & \sim \operatorname{Poisson}\left(\lambda_{i}\right) \\
\lambda_{i} & =\rho_{i} \times E_{i} \\
\eta_{i} & =\log \left(\rho_{i}\right)=\alpha \\
u_{i} & \sim \operatorname{Besag}
\end{array}
$$

Modelo BYM:

$$
\begin{array}{ll}
y_{i} \mid \lambda_{i} & \sim \operatorname{Poisson}\left(\lambda_{i}\right) \\
\lambda_{i} & =\rho_{i} \times E_{i} \\
\eta_{i} & =\log \left(\rho_{i}\right)=\alpha+u_{i}+\varepsilon_{i} \\
u_{i} & \sim \operatorname{Besag} \\
\varepsilon_{i} & \sim \operatorname{Normal}(0, \tau)
\end{array}
$$

Modelo Besag/CAR com efeito temporal de primeira ordem (RW1):

$$
\begin{array}{ll}
y_{i} \mid \lambda_{i} & \sim \operatorname{Poisson}\left(\lambda_{i}\right) \\
\lambda_{i} & =\rho_{i} \times E_{i} \\
\eta_{i} & =\log \left(\rho_{i}\right)=\alpha+\theta_{t}+u_{i} \\
\theta_{t} & =\theta_{t-1}+\varepsilon_{i} \\
u_{i} & \sim \operatorname{Besag} \\
\varepsilon_{i} & \sim \operatorname{Normal}(0, \tau)
\end{array}
$$

Modelo BYM com efeito temporal de primeira ordem (RW1):

$$
\begin{aligned}
y_{i} \mid \lambda_{i} & \sim \operatorname{Poisson}\left(\lambda_{i}\right) \\
\lambda_{i} & =\rho_{i} \times E_{i} \\
\eta_{i} & =\log \left(\rho_{i}\right)=\alpha+\theta_{t}+u_{i}+\varepsilon_{i} \\
\theta_{t} & =\theta_{t-1}+\varepsilon_{i} \\
u_{i} & \sim \operatorname{Besag} \\
\varepsilon_{i} & \sim \operatorname{Normal}(0, \tau) \\
\varepsilon_{i} & \sim \operatorname{Normal}(0, \tau) .
\end{aligned}
$$

Um fator importante que deve ser apontado é que, em todos os modelos, existe a restrição de que os efeitos espaço-temporais são separáveis. Isto é, existe a hipótese de que não há interação entre tendências temporais e espaciais. Esta restrição advém do fato de garantir uma parcimônia de 
parâmetros a serem estimados, uma vez que, caso interações fossem assumidas, matrizes que definiram o tipo de estrutura de interação teriam que ser optadas (Knorr-Held 1999, Blangiardo, Cameletti 2015).

Em termos de distribuições das prioris, adotou-se uma postura conservadora, em que todas as precisões (que podem ser vistas como o inverso da variância), tanto dos termos estruturados (modelo Besag) quanto dos não estruturados seguem uma distribuição Gama com parâmetros 1 e 0,0005, ou seja, $\frac{1}{\sigma^{2}}=\tau \sim \operatorname{Gama}(1 ; 0,0005) .{ }^{6}$ Por fim, com o intuito de comparar os modelos, duas medidas foram utilizadas.

A medida CPO (do inglês Conditional Predictive Ordinate) (Spiegelhalter et al. 1997) permite avaliar o poder preditivo dos modelos estimados, similar aos métodos de validação cruzada (Kohavi 1995), somando os valores estimados para cada ponto amostral, retirando-o da estimação do modelo. A estatística de resumo fornecida pelo critério de CPO é o $\operatorname{LPML}^{7}$ (do inglês, Logarithm of Pseudo Marginal Likelihood), que avalia o poder preditivo do modelo e, na sua especificação, baixos valores de LPML indicam um bom poder preditivo.

As medidas DIC (do inglês Deviance Information Criteria) (Gelfand, Dey, Chang 1992, Dey, Chen, Chang 1997) são utilizadas na modelagem de inferência Bayesiana para avaliar a qualidade do modelo estimado penalizando pela quantidade do número de parâmetros, similar às medidas de AIC (do inglês Akaike Information Criteria) (Akaike 1997). Elas fazem um ajuste balanceando o trade-off entre o erro de ajuste e a sobreparametrização. Sendo assim, quanto menor o seu valor, melhor é a qualidade do ajuste destes modelos.

${ }^{6} X \sim \operatorname{Gama}(\alpha ; \beta) \Rightarrow E(X)=\alpha / \beta$.

${ }^{7} L P M L=-\sum_{i=1}^{n} \log \left\{\pi\left(y_{i} \mid \mathbf{y}_{-i}\right)\right\}$ 


\subsection{Agregação do Índice}

De posse das estimativas geradas das ocorrências, apresenta-se o indicador geral de criminalidade combinando as estimativas. Conforme será visto na Seção 3.2, vamos ponderá-lo de acordo com a sua menor pena ${ }^{8}$ prevista em no Código Penal. Sendo assim, o índice da região $i$ tem um formato simples conforme a Equação 11:

$$
\operatorname{ICrimeRS}_{i}=\frac{\sum_{j=1}^{k} y_{i j} \times w_{j}}{\text { População } o_{i}} \times 365
$$

onde a variável $j$ é o indexador de tipo de crime (que varia de 1 até $k$ ), $y$ é a quantidade de ocorrência criminal e $w$ é o pena mínima prevista em lei de acordo com a Tabela 3.1.

\subsection{ICrimeRS: Interpretação, Vantagens e Desvantagens}

Vale destacar aqui algumas discussões específicas do indicador proposto neste ensaio, uma vez que ele possui características únicas na literatura. Além da abordagem INLA utilizada, o que permite englobar efeitos espaciais e temporais de maneira rápida e eficiente em um modelo bayesiano, será de interesse também estimar o índice para diferentes classes de crimes, a saber, contra a vida e contra o patrimônio. Neste sentido, diferentes utilizações para ele podem ser dadas dependendo da ótica da análise. Por exemplo, uma seguradora pode querer precificar seus serviços de acordo com uma medida de criminalidade contra o patrimônio de uma determinada região, enquanto que o gestor público pode ter um interesse maior em reduzir o número de mortes devido à criminalidade.

Ademais, uma grande vantagem do indicador é a interpretabilidade e comunicabilidade do seu valor. A soma do numerador representa a soma da pena mínima que o agressor de cada ocorrência deveria cumprir, em tese, de uma determinada região $i$. Por exemplo, supondo que o índice é composto apenas por latrocínio e homicídio e num determinado ano

8 Acredita-se que grande parte dos criminosos condenados não cumpre toda a pena sentenciada e, portanto, optou-se por escolher pela menor pena prevista. Ademais, a escolha de outro valor entre o intervalo penal poderia ampliar a magnitude destes pesos devido a heterogeneidade de amplitudes entre os diferentes crimes. 
houveram 2 latrocínios e 10 homicídios. Este numerador resultaria em $2 \times 20+10 \times 6=100$ anos de reclusão se todos fossem condenados pela pena mínima. Para padronização do número, divide-se por toda a população e multiplica-se por 365 para dar o resultado em dias para melhorar a interpretabilidade. Exemplificando para um município, o indicador pode responder a seguinte pergunta: "Supondo que todos os crimes sejam julgados e condenados pela pena mínima, em Porto Alegre, quantos dias do ano cada habitante Porto Alegrense teria que passar na cadeia para pagar por todos os crimes cometidos?". Ou seja, se o ICrimeRS de Porto Alegre for 50 para um determinado ano, isso significa que, em média, todos os habitantes teriam que passar 50 dias presos para pagar pelos crimes cometidos em um cenário em que houvesse todas condenações mínimas. ${ }^{9}$ Esta interpretação se configura uma grande vantagem, vis-à-vis a simplesmente sumarizar o grau criminal numa escala que não possui interpretação prática como, por exemplo, entre 0 e 1 como em Freitas, Cadaval e Gonçalves (2016).

Vale ressaltar que a presente proposta de indicador possui limitações. Evidentemente que a hipótese de todos os crimes serem julgados e condenados é muito forte. Sabe-se que, por exemplo, grande parte dos homicídios cometidos não é resolvida ou demoram consideravelmente até o seu julgamento. Adicionalmente, uma característica importante, que não está sendo levada em consideração, é a possibilidade de reincidência da mesma pessoa em determinado crime. Por exemplo, é possível que uma mesma pessoa (ou grupos de pessoas) seja responsável por mais de uma ocorrência de roubo num ano em uma região (ou várias regiões). No entanto, mesmo com estas ressalvas, a interpretabilidade e a relevância do indicador ainda é mantida, uma vez que ele não mede eficiência policial ou jurídica, mas sim a realização do fato criminal de uma determinada região e ano.

\section{Base de Dados, Penas Criminais e Estatísticas Descritivas}

\subsection{Base de Dados}

A base de dados utilizada compila informações de ocorrências criminais disponibilizados pela Secretaria de Segurança Pública do Rio Grande do

9 A fim de ilustrar em termos rentáveis. Em 2014, segundo a Fundação de Economia e Estatística, o PIB per capita de Porto Alegre chegou a $\mathrm{R} \backslash \$ 43.457,67$. Portanto, sob algumas hipóteses, a perda de PIB per capita, caso cada Porto Alegrense passasse 50 dias encarcerado, seria de $\mathrm{R} \backslash \$ 5.953,11$. 
Sul ${ }^{10}$ (SSP-RS), que possui vínculo com órgãos como a Brigada Militar, Polícia Civil, Superintendência de Serviços Penitenciários e Instituto Geral de Perícias. Segundo Monteiro (2009), em 2007 foram instituídos, pelo então secretário José Franscisco Mallmann, 13 indicadores que tinham como objetivo retratar a realidade criminal no estado. Estes indicadores incluem as seguintes classes criminais: homicídio doloso, furto, furto de veículo, roubo, latrocínio, roubo de veículo, extorsão, extorsão mediante sequestro, estelionato, delitos relacionados à corrupção, delitos relacionados a armas e munições, posse de entorpecentes e tráfico de entorpecentes. Todas as ocorrências abrangem todos os 496 municípios do estado ${ }^{11}$ e os dados são anuais, iniciados em 2002. Neste estudo, no entanto, somente alguns crimes foram utilizados para a criação do índice geral de criminalidade, pois o objetivo é usar um conjunto de delitos que afetam diretamente o cotidiano do bem-estar social no que tange à relação direta entre a perda de um bem ou a vivência de um trauma devido ao contato direto interpessoal com o agressor resultando somente no uso do homicídio doloso (HomDol), roubo (Roub), roubo de veículos (RoubVei), latrocínio (Latro), furto (Furt), furto de veículos (FurtVei) e extorsão mediante sequestro (ExtoMS).

\subsection{Penas Criminais}

Com relação às ponderações criminais, optou-se por seguir Freitas, Cadaval e Gonçalves (2016), que fizeram uso da previsão da pena em termos de período de reclusão de acordo com o Código Penal Brasileiro, conforme a Tabela 3.1. Vale destacar que o código penal é bem específico em termos penais para diferentes tipos de crime. Por exemplo, no caso do furto ${ }^{12}$ (reclusão, de um a quatro anos), é possível classificá-lo como qualificado (reclusão de dois a oito anos) ou de coisa comum (detenção, de seis meses a dois anos). No entanto como não é possível saber qual a subcategoria do furto na base de dados da SSP-RS, optou-se por adotar a pena do grupo de maior nível hierárquico.

\footnotetext{
${ }^{10}$ A base pode ser acessada no link http://www.ssp.rs.gov.br/ ou também na base de dados FEEDADOS da Fundação de Economia e Estatística através do link http://feedados.fee.tche.br/

${ }^{11} \mathrm{O}$ município de Pinto Bandeira foi excluído deste trabalho, uma vez que sua criação foi somente a partir do ano de 2013.

${ }^{12}$ Artigo 155 - Subtrair, para si ou para outrem, coisa alheia móvel.
} 
Tabela 3.1 - Penas dos crimes considerados no índice

\begin{tabular}{lcc}
\hline \multicolumn{1}{c|}{ Crime } & Penas \\
\hline Homicídio Doloso & 6 a 20 \\
Furto & $1 \mathrm{a} 4$ \\
Furto de Veículo & $1 \mathrm{a} 4$ \\
Roubos & 4 a 10 \\
Latrocínio & 20 a 30 \\
Roubo de Veículo & 4 a 10 \\
Extorsão mediante sequestro & 8 a 15 \\
\hline
\end{tabular}

Fonte: Elaboração própria.

\subsection{Estatísticas Descritivas}

A Figura 3.1 apresenta a evolução da taxa por 100.000 habitantes do homicídio doloso no estado do Rio Grande do Sul. Primeiramente, ressalta-se que o patamar em que esta série se encontra já é elevado uma vez que o seu valor mínimo, obtido no ano de 2004, é de 12,39 o que representa um número maior que o máximo considerado aceitável pela Organização das Nações Unidas (ONU), que classifica como violência epidêmica quando há mais de 10 mortes violentas para cada 100.000 habitantes. ${ }^{13}$ Nesta figura podemos verificar a preocupante tendência crescente destas taxas principalmente a partir do ano de 2012 e alcançando o valor de 21,6 em 2015.

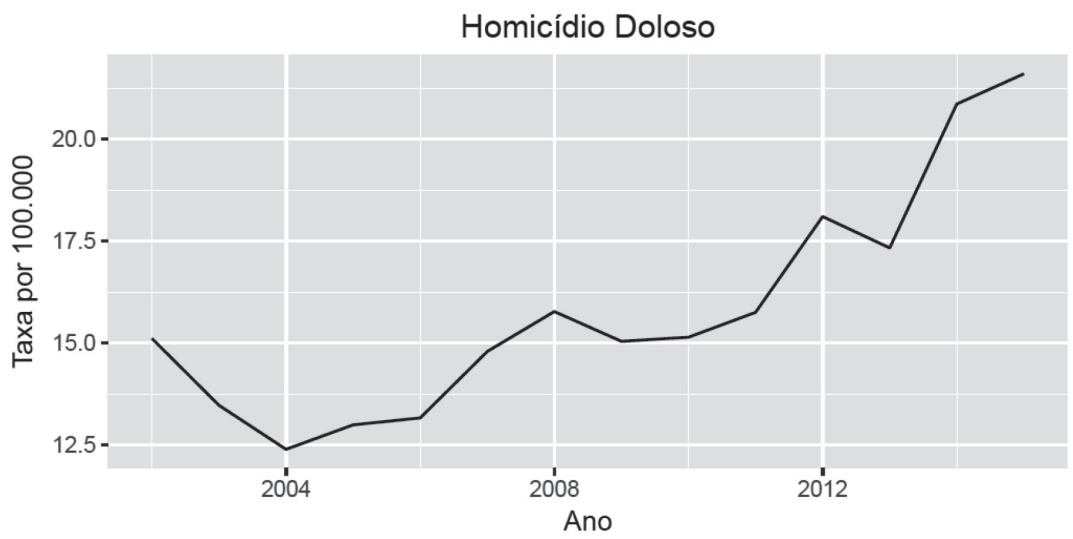

Figura 3.1 - Evolução do Homicídio Doloso no Rio Grande do Sul

Fonte: SSP-RS e FEE.

${ }^{13}$ http://noticias.uol.com.br/cotidiano/ultimas-noticias/2013/11/05/todos-os-estados-do-pais-tem-assassinatos-em-niveis-epidemicos-aponta-estudo.htm 
Para os demais crimes do estado, a Figura 3.2 apresenta a dinâmica evolutiva separadamente. Pelas magnitudes das taxas, é possível observar que o tipo de crime que tem o maior número de registros é o Furto, que alcançou uma marca de 2431,6 casos por 100.000 habitantes no ano de 2003, mas posteriormente, esta série apresenta uma acentuada queda ao longo dos anos. O Roubo é o segundo crime com maior patamar, oscilando entre os valores de 405,81 em 2011 e impressionantes 703,35 em 2015. É interessante analisar a dinâmica que o roubo apresentou no RS, em formato de $U$, tendo seu início logo após o ano de 2007, mas alcançando valores consideráveis ao seu final. Esta característica em formato de $U$ também é observada nos crimes de Roubo de Veículos, Latrocínio e Furto de Veículos, sendo todos eles tendo início em períodos similares perto de 2006 e ascensões após o ano de 2010. Esta característica vai contra a impressão de que em geral as pessoas têm de que a criminalidade "está sempre aumentando". Os dados estaduais não apontam nesta direção, indicando algum acontecimento nestes períodos indicados. Por fim, mas não menos importante, observase a evolução errática da quantidade de extorsões mediante sequestro. Este tipo de crime se apresenta com menor grau de ocorrência criminal tendo taxas, em sua maior parte, menores que 0,3 casos por 100.000 habitantes. Para se ter noção da magnitude e da esparsidade da matriz de dados deste tipo de crime, em 2015 houve 18 registros e em 2014 (o maior valor da série histórica) registrou-se 37 casos em todo o estado.
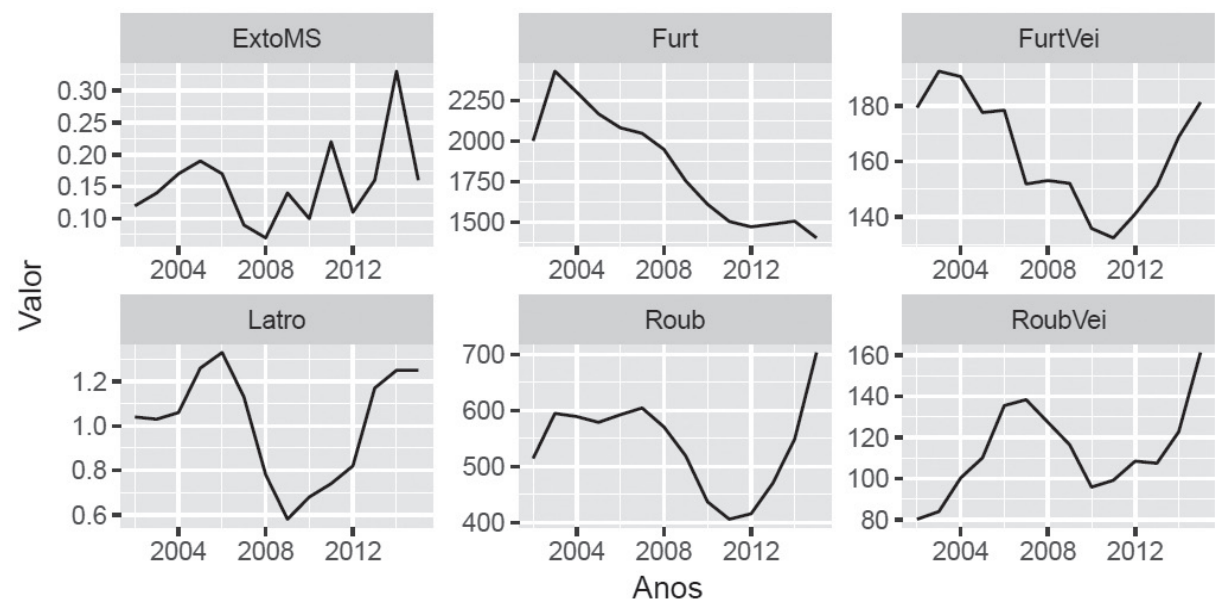

Figura 3.2 - Evolução de crimes selecionados no Rio Grande do Sul, 2002-2015 Fonte: SSP-RS e FEE. 
As Figuras 3.3 e 3.4 mostram a evolução dos crimes separados pelas cinco maiores cidades do RS, a saber, Porto Alegre, Caxias do Sul, Canoas, Pelotas e Santa Maria, respectivamente. A dinâmica evolutiva dos crimes é muito similar à apresentada no estado, tendo em vista que grande parte dos crimes acontece nestas cidades. Somente na capital, Porto Alegre, para o ano de 2015, as ocorrências de homicídios representaram 24\% de todo o estado. Para os demais crimes e representação também foi acentuada. ${ }^{14}$

É importante notar que as dinâmicas da Figura 3.4 são similares à do estado, onde todos os maiores municípios apresentaram queda em $U$ nos crimes de Roubo, Roubo de Veículos e Latrocínio e queda nos furtos. Por outro lado, o formato em $U$ dos furtos de veículos não é ilustrado quando mostrados somente estes municípios, pois ele foi causado basicamente pelos municípios de Porto Alegre, Canoas, São Leopoldo (3,9\% dos casos no estado em 2015), Santa Cruz do Sul (3,2\% dos casos no estado em 2015) e Passo Fundo (3,1\% dos casos no estado em 2015).

Algumas das principais hipóteses acerca desta característica do formato em $U$ de diversos municípios e no RS são discutidas em Kerber e Pazinato (2016). A principal é a de que esta característica tem estreita relação com a implementação do Programa Nacional de Segurança Pública com Cidadania (PRONASCI) no RS, em especial, na Região Metropolitana de Porto Alegre. ${ }^{15}$ Além disto, neste período, diversas operações atreladas à repressão qualificada foram feitas. Na RMPA, em 2009, aconteceu a Operação Cova Rasa que fez diversas prisões estratégicas. Outros pontos discutidos foram as criações dos territórios de paz, os projetos sociais, Mulheres da Paz e Justiça Comunitária, construídos e financiados pela SENASP/Ministério da Justiça em muitos municípios. Outro fator que é levantado é o de que neste período foi realizada a estruturação dos Gabinetes de Gestão Integrada Municipal (GGIM) e das áreas com videomonitoramento e de audiomonitoramento.

Além disso, foi criado o Índice de Municipalização da Segurança Pública (IMUSP). Notou-se que Canoas e Esteio foram os municípios com maior IMUSP. Argumenta-se que quanto maior o IMUSP, maior a redução de crimes patrimoniais, roubos e furtos em geral, atrelados à sensação de segurança. ${ }^{16}$ Kerber e Pazinato (2016) dizem que a gestão da informação

\footnotetext{
${ }^{14}$ Porto Alegre teve 39\% de roubos, 52\% de roubo de veículos, 26\% de latrocínios, 20\% de furtos, 21\% de furto de veículos e $11 \%$ de extorsões mediante sequestro.

15 Também discutida em Cidade (2012).

${ }^{16}$ Apesar do medo estar relacionado com a vitimização.
} 
e a integração das polícias com as Guardas Municipais foram decisivos no período de 2010 a 2012 e notaram que os municípios com mais ações do PRONASCI foram os que mais reduziram crimes, exceto os crimes letais, como homicídios. Por fim, os autores fazem a ressalva de que a dinâmica da produção das violências é multicausal e multifatorial. Ou seja, existem outros fatores que influenciaram, como a criação de secretarias de segurança municipais, a centralidade da agenda pública e política e a conjuntura econômica e política.

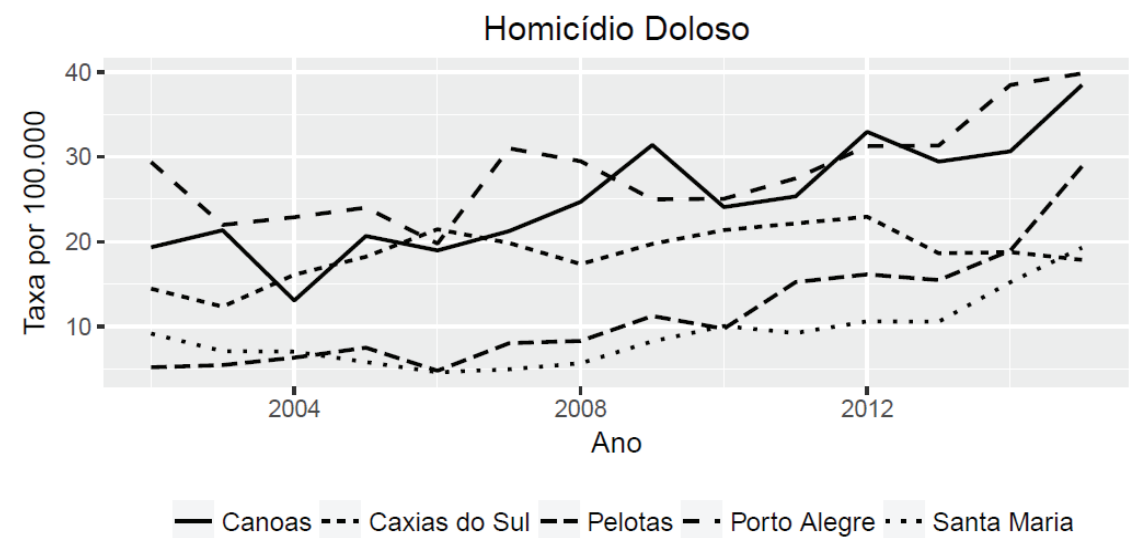

Figura 3.3 - Evolução de homicídios nos cinco maiores municípios Fonte: SSP-RS e FEE.

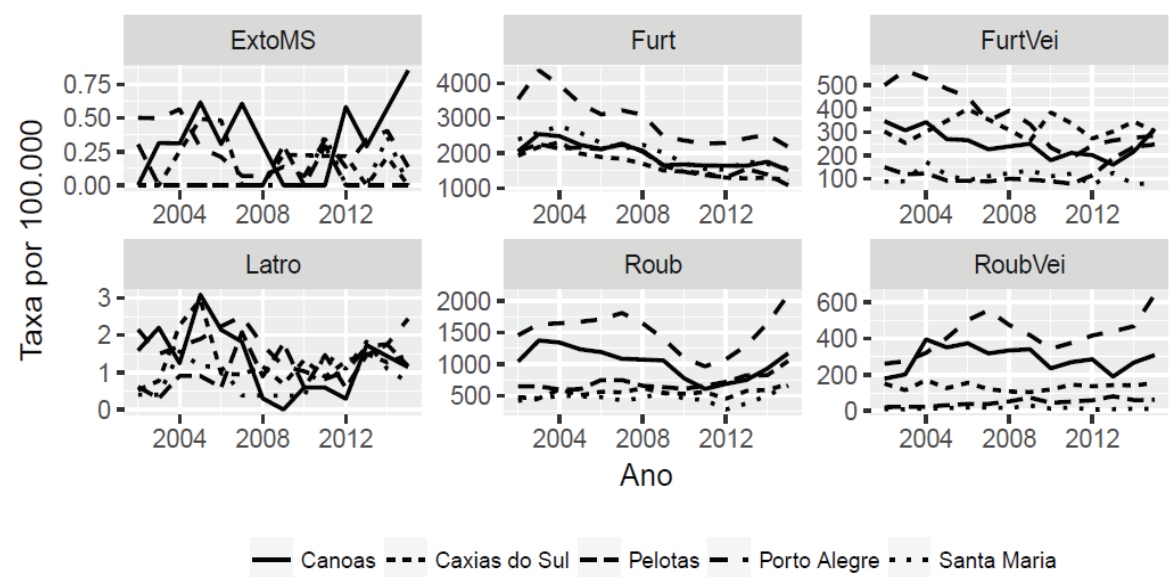

Figura 3.4 - Evolução de crimes selecionados nos cinco maiores municípios Fonte: SSP-RS e FEE. 
Tabela 3.2 - Estatísticas Descritivas de crimes selecionados, 2015

\begin{tabular}{ccccccc}
\hline Crime & Min. & 1ㅇ. & Mediana & Média & 3 Q. & Máx \\
\hline Roub & 0.00 & 31.10 & 73.71 & 137.52 & 157.10 & 2097.96 \\
RoubVei & 0.00 & 0.00 & 0.00 & 26.35 & 30.26 & 642.40 \\
Latro & 0.00 & 0.00 & 0.00 & 0.62 & 0.00 & 24.27 \\
Furt & 0.00 & 696.70 & 959.69 & 1077.87 & 1325.01 & 5689.20 \\
HomDol & 0.00 & 0.00 & 0.00 & 10.01 & 17.25 & 90.99 \\
FurtVei & 0.00 & 18.59 & 50.83 & 70.24 & 92.68 & 500.63 \\
ExtoMS & 0.00 & 0.00 & 0.00 & 0.04 & 0.00 & 9.18 \\
\hline
\end{tabular}

Fonte: Elaboração própria.

Tabela 3.3 - Ranking municipal de taxas criminais - 2015

\begin{tabular}{cccccc}
\hline Crime & 10 lugar & 20 lugar & 30 lugar & 40 lugar & 5o lugar \\
\hline Roub & Porto Alegre & Alvorada & Cachoeirinha & Esteio & Novo Hamburgo \\
RoubVei & Porto Alegre & Novo Hamburgo & Cachoeirinha & São Leopoldo & Canoas \\
Latro & Riozinho & Cerro Branco & Caiçara & Campinas do Sul & Maquiné \\
Furt & Xangri-lá & Arroio do Sal & Imbé & Balneário Pinhal & Cidreira \\
HomDol & Esmeralda & Entre Rios do Sul & Ponte Preta & Porto Vera Cruz & Campestre da Serra \\
FurtVei & Santa Cruz do Sul & Campo Bom & Novo Hamburgo & Tramandaí & Bento Gonçalves \\
ExtoMS & Terra de Areia & Parobé & Novo Hamburgo & Alvorada & Canoas \\
\hline
\end{tabular}

Fonte: Elaboração própria.

As Tabelas 3.2 e 3.3 apresentam, respectivamente, as principais estatísticas descritivas de cada um dos crimes e os cinco municípios que apresentam as maiores taxas em 2015. Estas tabelas refletem apenas um retrato transversal da estrutura criminal do estado do Rio Grande do Sul, pois seus valores e rankings podem variar substancialmente entre cada um dos anos. Uma das características que mais chamam a atenção na primeira tabela é a quantidade expressiva de zeros de medidas de locação (em especial, primeiro quartil, mediana e terceiro quartil) de diversos crimes, o que reflete a grande esparsidade da matriz de dados onde diversos municípios 
simplesmente não registram ocorrências criminais destas classificações. Em termos de rankings municipais, por exemplo, Porto Alegre, Alvorada e Cachoeirinha ficaram com as três primeiras posições no ranking de roubos; Porto Alegre, Novo Hamburgo e Cachoeirinha no roubo de veículos; Riozinho, Cerro Branco e Caiçara no latrocínio e os demais rankings podem ser visualizados.

Chama a atenção o nome de municípios atípicos no topo destas listas como o município de Esmeralda, Entre Rios do Sul e Ponte Preta para homicídios dolosos, assim como os três mencionados anteriormente para o crime de latrocínio. O município de Esmeralda, que fica próximo à fronteira nordeste do estado, apresentou a impressionante taxa de homicídios de 90,99, sendo que neste ano este município teve somente três homicídios, mas com uma população de apenas 3.297. ${ }^{17}$ Já para o ano de 2013, o município líder em taxa de homicídios é o pequeno município do centro do estado, São José do Herval. Este município tinha uma população de 2.123 habitantes e apenas três casos, o que resultou em uma taxa de $141,31 .{ }^{18}$ Neste mesmo ano, São José do Inhacorá teve três casos, alcançando uma taxa de 135,14 homicídios por 100.000 habitantes. ${ }^{19}$ Para o crime de latrocínio, a ocorrência de apenas um caso em Riozinho em 2015 (com população de 4.121) foi suficiente para colocá-lo no topo da lista alcançando uma taxa de $24,3 .{ }^{20} \mathrm{O}$ mesmo caso ocorre com o município de Muliterno, com 1.879 habitantes, que também apresentou somente um caso de latrocínio em toda a série, em 2014, representando uma taxa de 53,2 por 100.000 habitantes.

Já para os crimes que acontecem com uma frequência maior como roubo e roubo de veículos, os municípios mais populosos ficam no topo do ranking das taxas. Alguns destaques que podem ser levados em consideração são o município de Tio Hugo (população de 2.855), que teve sete roubos de carros em 2015, resultando numa taxa de 245,18, e Ciríaco (4.813 habitantes), que teve 17 roubos em 2014 (taxa de 353,21). Em termos de furtos e furtos de veículos a principal característica a ser observada é a elevada presença de municípios litorâneos, que se observam também nos demais anos e não somente em 2015, como Xangri-lá, Arroio do Sal, Imbé, Cidreira, Tramandaí e Balneário Pinhal.

\footnotetext{
${ }^{17}$ Esmeralda apresentou somente um homicídio em 2003, 2005, 2006, 2007 e 2009, obtendo um outlier de três casos em 2015.

18 São José do Herval apresentou somente um homicídio em 2002, 2005, 2007 e 2014, obtendo um outlier de três casos em 2013.

19 O único outro caso de homicídio foi em 2008.

${ }^{20}$ Este foi o único caso de latrocínio neste município em toda a série histórica.
} 
Cortes (2016) argumenta que "grande parte dos registros de ocorrência se dá quando o patrimônio suprimido possui valor significativo para a vítima". Além disso, argumenta que "Em geral, os furtos pequenos (como o de bolsas, celulares, relógios, etc.), que ocorrem em centros urbanos, não são registrados pelas vítimas, talvez por descrença no sistema judiciário em punir o infrator ou pela falta de disposição de se dirigir a uma delegacia por objetos de menor valor. No entanto, em cidades litorâneas (...) tanto as taxas de furto quanto as de furtos de veículos são relativamente maiores. Isso pode se relacionar ao fato de que, devido ao componente sazonal, grande parte das residências litorâneas fique vazia ao longo do ano, propiciando, conforme a Teoria das Janelas de Oportunidade, a subtração ilícita de bens, sem que haja relação interpessoal com a vítima." Esta questão da sazonalidade e as evidências de subestimação do fluxo de pessoas no litoral do estado, o que superestima as taxas de furtos de municípios litorâneos, são discutidas em Zuanazzi e Bartels (2016).

Recentemente, uma ferramenta que possibilita a visualização dos dados de criminalidade do Rio Grande do Sul, a partir de séries temporais, gráficos de relação, mapas, assim como autocorrelações espaciais (para diferentes especificações da matriz de vizinhança), é o CrimeVis da Fundação de Economia e Estatística. Nesta ferramenta, é possível navegar e interagir dinamicamente entre as diferentes opções de visualização dos dados aqui apresentados. O CrimeVis pode ser acessado em visualiza.fee.tche.br/ crime. $^{21}$

${ }^{21}$ Acessado em 20/09/2017. 


\section{Resultados}

Os modelos estimados segundo a Seção 2.4 foram comparados fazendo uso do DIC e do LPML. Os valores do LPML se encontram na Tabela 4.1.

Tabela 4.1 - LPML para diferentes especificações e diferentes matrizes

\begin{tabular}{|c|c|c|c|c|c|c|c|c|}
\hline Matriz & Especificação & Roubo & RouboVei & Latro & Furto & HomDol & FurtVei & ExtoMS \\
\hline Cont. (1르) & Besag & 25419.99 & 11742.86 & 2075.90 & 52413.51 & 8021.24 & 22301.31 & 590.16 \\
\hline Cont. (1르) & BYM & 25419.01 & 11741.85 & 2075.66 & 52413.63 & 8020.62 & 22300.33 & 590.16 \\
\hline Cont. (1aㅡ) & Besag + RW1 & 25444.43 & 11805.33 & 2076.24 & 52368.41 & 8023.76 & 22237.35 & 590.21 \\
\hline Cont. (1를 & $\mathrm{BYM}+\mathrm{RW} 1$ & 25442.21 & 11800.29 & 2076.03 & 52370.02 & 8023.52 & 22234.19 & 590.22 \\
\hline k-NN (1르) & Besag & 29184.34 & 17460.42 & 2147.53 & 52415.55 & 9527.48 & 24611.89 & 623.52 \\
\hline k-NN $\left(1^{a}\right)$ & BYM & 28735.78 & 16916.85 & 2134.61 & 52541.77 & 9338.64 & 24262.77 & 616.78 \\
\hline k-NN $\left(1^{a}\right)$ & Besag + RW1 & 29194.09 & 17558.20 & 2147.76 & 52370.63 & 9520.94 & 24517.45 & 623.59 \\
\hline k-NN (1 $\left.{ }^{a}\right)$ & $\mathrm{BYM}+\mathrm{RW} 1$ & 28744.92 & 16983.56 & 2134.44 & 52475.20 & 9336.73 & 24143.70 & 618.19 \\
\hline k-NN $\left(2^{a}\right)$ & Besag & 25425.73 & 12376.43 & 2155.34 & 52413.47 & 9601.24 & 22312.34 & 625.27 \\
\hline k-NN $\left(2^{a}\right)$ & BYM & 116942.77 & 58923.96 & 2170.16 & 88132.22 & 10244.07 & 49997.24 & 626.30 \\
\hline k-NN $\left(2^{a}\right)$ & Besag + RW1 & 25449.27 & 12437.28 & 2155.35 & 52370.74 & 9598.03 & 22368.72 & 625.27 \\
\hline k-NN $\left(2^{a}\right)$ & $\mathrm{BYM}+\mathrm{RW} 1$ & 28318.18 & 33458.38 & 2170.29 & 56544.52 & 10263.77 & 33539.89 & 626.30 \\
\hline k-NN $\left(3^{a}\right)$ & Besag & 25423.06 & 12342.54 & 2157.44 & 52412.85 & 8726.26 & 22305.15 & 624.44 \\
\hline 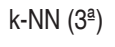 & BYM & 116979.91 & 58353.86 & 2172.73 & 90182.97 & 10329.64 & 49515.16 & 626.32 \\
\hline k-NN (3aㅗ & Besag + RW1 & 25447.32 & 12412.15 & 2157.35 & 52368.22 & 8699.60 & 22241.59 & 624.59 \\
\hline 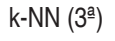 & BYM + RW1 & 25565.82 & 33097.15 & 2172.89 & 56663.46 & 10369.80 & 33618.43 & 626.37 \\
\hline
\end{tabular}

Fonte: Elaboração Própria. 
Os valores do DIC para os modelos estimados podem ser vistos na Tabela 4.2 .

Tabela 4.2 - DIC para diferentes especificações e diferentes matrizes

\begin{tabular}{|c|c|c|c|c|c|c|c|c|}
\hline Matriz & Especificação & Roubo & RouboVei & Latro & Furto & HomDol & FurtVei & ExtoMS \\
\hline Cont. (1르) & Besag & 49748.71 & 22952.88 & 4150.39 & 100654.70 & 15975.00 & 44451.91 & 1179.17 \\
\hline Cont. (1 $\left.1^{\mathrm{a}}\right)$ & BYM & 49746.27 & 22949.99 & 4149.81 & 100654.47 & 15973.04 & 44448.67 & 1179.15 \\
\hline Cont. (1 $\left.1^{a}\right)$ & Besag + RW1 & 49690.41 & 22947.45 & 4151.02 & 100477.84 & 15977.64 & 44462.45 & 1179.24 \\
\hline Cont. (1 $\left.1^{a}\right)$ & $B Y M+R W 1$ & 49688.18 & 22944.77 & 4150.55 & 100478.17 & 15977.30 & 44458.96 & 1179.24 \\
\hline k-NN (1aㅡ) & Besag & 57239.63 & 34319.00 & 4294.40 & 100663.69 & 19005.37 & 49155.42 & 1246.90 \\
\hline k-NN (1aㅡ) & BYM & 56362.48 & 33239.63 & 4269.43 & 100983.19 & 18632.38 & 48445.20 & 1233.44 \\
\hline k-NN (1르) & Besag + RW1 & 57165.47 & 34294.24 & 4294.73 & 100496.22 & 18990.73 & 49141.97 & 1247.01 \\
\hline k-NN (1a) & $B Y M+R W 1$ & 56295.99 & 33190.24 & 4269.00 & 100767.21 & 18627.23 & 48408.08 & 1236.17 \\
\hline k-NN (2a $)$ & Besag & 49772.66 & 24302.50 & 4309.83 & 100657.15 & 19152.10 & 44485.44 & 1250.52 \\
\hline k-NN (2 $\left.2^{-a}\right)$ & BYM & 231142.70 & 116952.17 & 4339.80 & 171989.60 & 20455.88 & 99960.90 & 1252.56 \\
\hline k-NN ( $\left(2^{a}\right)$ & Besag + RW1 & 49714.19 & 24279.69 & 4309.76 & 100478.71 & 19144.05 & 44785.79 & 1250.50 \\
\hline k-NN (2a $)$ & $\mathrm{BYM}+\mathrm{RW} 1$ & 55449.86 & 65740.68 & 4340.06 & 108971.87 & 20493.95 & 67182.64 & 1252.56 \\
\hline k-NN (3르) & Besag & 49768.63 & 24236.07 & 4313.94 & 100656.60 & 17403.92 & 44472.25 & 1248.83 \\
\hline k-NN (3르) & BYM & 231313.12 & 115829.00 & 4345.05 & 175962.87 & 20625.67 & 99200.93 & 1252.61 \\
\hline k-NN (3 $\left.3^{a}\right)$ & Besag + RW1 & 49710.14 & 24229.56 & 4313.71 & 100479.81 & 17349.44 & 44482.71 & 1249.10 \\
\hline k-NN (3 $\left.3^{a}\right)$ & BYM + RW1 & 49996.59 & 65035.74 & 4345.36 & 109202.52 & 20705.62 & 67400.28 & 1252.72 \\
\hline
\end{tabular}

Fonte: Elaboração Própria.

Com base nestes resultados, nota-se que a maioria dos modelos apontados por ambos os critérios são modelos que fazem uso da estrutura de vizinhança supondo matriz de contiguidade de $1^{\mathrm{a}}$ ordem. Os critérios de LPML apontaram para o modelo BYM em todos os crimes, com exceção do Furto de Veículos que apontou para o modelo BYM+RWl. Uma peculiaridade deste critério foi a de que, para o Furto, ele apontou para o modelo Besag+RWl supondo estrutura de vizinhança com 3 vizinhos mais próximos. Já com relação ao critério do DIC, os modelos apontados foram BYM+RWl, BYM+RWl, BYM, Besag+RWl, BYM, BYM e BYM para, respectivamente, os crimes de Roubo, Roubo de Veículos, Latrocínio, Furto, Homicídio Doloso, Furto de Veículos e Extorsão Mediante Sequestro. 
Uma coisa que é importante chamar a atenção é a de que, para a extorsão mediante sequestro, e para os dois crimes contra a vida (homicídio doloso e latrocínio), os critérios apontaram para o mesmo modelo (BYM). Tendo em vista que o critério de construção do LPML é objetivamente a capacidade preditiva do modelo, ele foi utilizado como critério de desempate para os demais crimes. Sendo assim, as abordagens resultantes foram BYM (Roubo), BYM (Roubo de Veículos), BYM (Latrocínio), Besag+RW1 (Furto), BYM (Homicídio Doloso), BYM+RWl (Furto de Veículos) e BYM (Extorsão Mediante Sequestro). Todos eles supondo vizinhos de contiguidade de $1^{\mathrm{a}}$ ordem, com exceção do Furto.

A Figura 4.1 mostra a relação de ocorrência entre as estimativas do modelo e dos dados brutos. Apesar de existir um cluster de pontos destacado nos cantos superiores direitos da maioria dos gráficos, representando os 14 anos de Porto Alegre, aparentemente existe uma relação direta entre o INLA e o número de ocorrências em cada um dos crimes. Uma característica que foi avaliada foi a de que as estimativas obtidas pelo método INLA sobresuavizaram as estimativas e, portanto, optou-se por utilizar dois terços de seu peso para os valores estimados e um terço para os verdadeiros valores como proxy do número de ocorrências. ${ }^{22}$
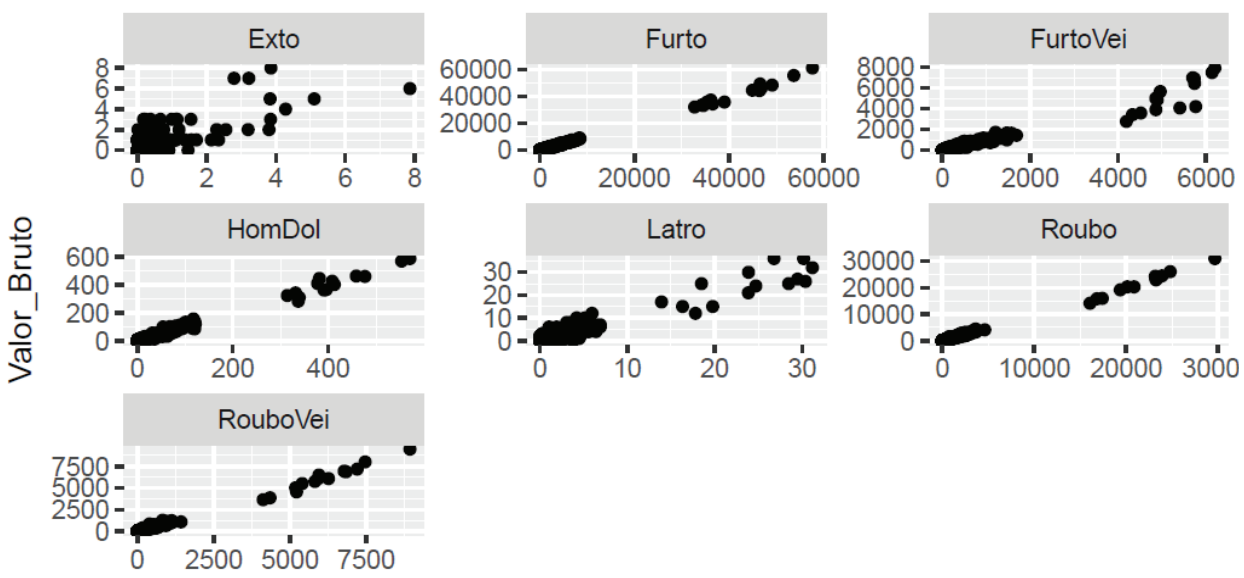

Valor_INLA

Figura 4.1 - Relação entre ocorrência estimada pelos modelos do INLA e ocorrência bruta (todos os anos e todos os municípios)

Fonte: SSP-RS e elaboração própria.

22 O critério de definição do peso foi definido a fim mitigar o efeito de sobre suavização. 
As Figuras 4.2 e 4.3 ilustram o efeito do método utilizado na estimação do número de ocorrências esperado em cada região para homicídio e latrocínio. Nas duas figuras estão presentes um município representativo (Pelotas no primeiro e Alvorada no segundo) e três municípios mais problemáticos. É importante observar que a volatilidade não é eliminada, mas existe uma suavização dos seus valores, bem como a presença de valores não nulos quando o número de ocorrências é zero. Visualmente é possível ver que para o município de Esmeralda, por exemplo, o número de ocorrência é não nulo para os anos próximos a 2012 e apresentaria menos de 2 casos de homicídio em 2015. Complementarmente, na Figura 4.3 o município de Riozinho apresenta valores não nulos para toda a sua série histórica mostrando que, apesar de não ter tido nenhum latrocínio até 2015, existia uma probabilidade remota de acontecer pelo método usado.

\section{Homicídios Comparativos}

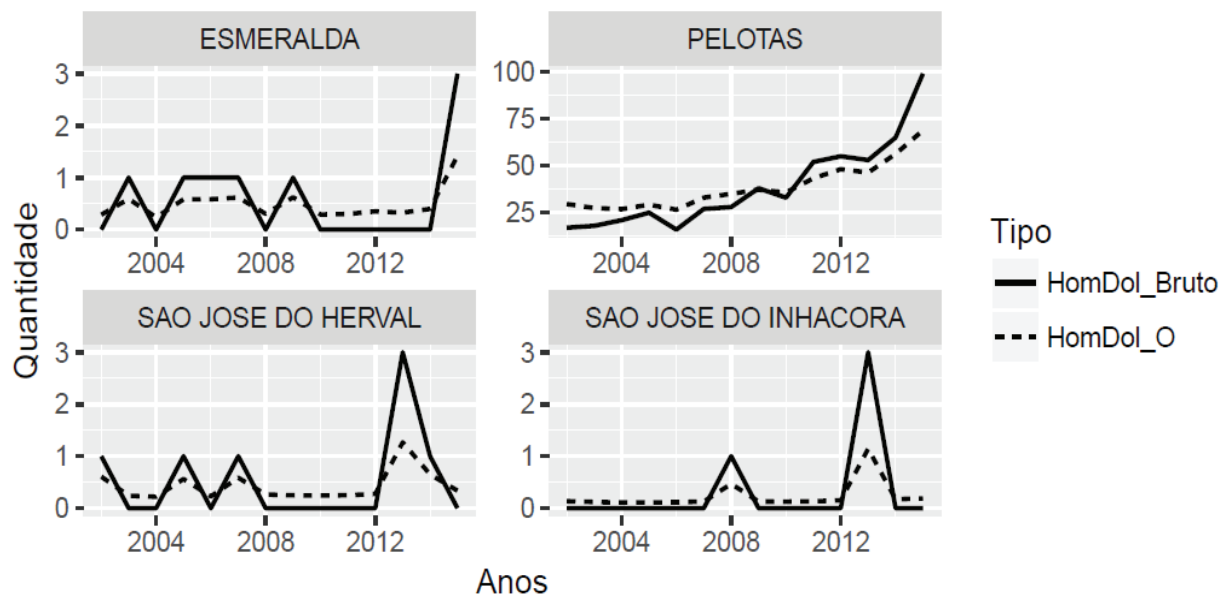

Figura 4.2 - Comparação de Número de Homicídios de municípios selecionados Fonte: SSP-RS e elaboração própria. 


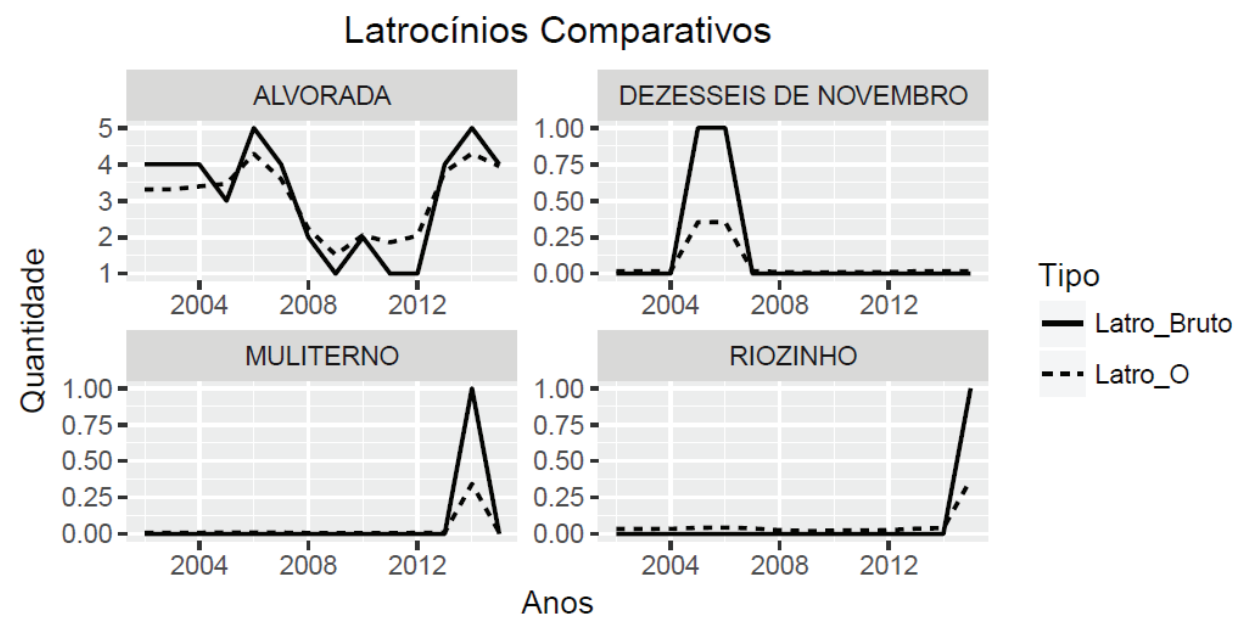

Figura 4.3 - Comparação de Latrocínios de municípios selecionados Fonte: SSP-RS e elaboração própria.

Uma das características desejadas do índice é, além de apresentar uma medida geral de criminalidade, poder segregar o indicador em dois tipos de crime: contra a vida e contra o patrimônio. Os crimes contra a vida compreendem os homicídios dolosos e os latrocínios, enquanto que os crimes contra o patrimônio referem-se aos cinco restantes. As Figuras 4.4 e 4.5 apresentam os principais resultados para dois conjuntos de municípios, onde ambas as figuras apresentam os resultados para o índice geral de criminalidade e os índices de crimes contra a vida e crimes contra o patrimônio.

A Figura 4.4 apresenta alguns dos principais municípios gaúchos evoluindo no tempo de acordo com cada um dos indicadores. A primeira característica a se notar no primeiro gráfico à esquerda é um padrão similar de comportamento caracterizado por um aumento nos anos iniciais, uma redução em meados de 2011 e 2012 e seguido de um avanço subsequente.

Porto Alegre é o município que apresenta o maior índice de criminalidade geral. Em termos de interpretabilidade, em 2015, o índice apresentou um valor de 49,15, o que significa que cada Porto Alegrense deveria, em média, passar entre 49 e 50 dias dentro da cadeia neste ano para pagar por todos os crimes cometidos, supondo-se a condenação pela pena mínima prevista na lei brasileira. No entanto, ao analisar a desagregação de crimes contra 
o patrimônio e contra a vida, verificamos que quase 98\% deste indicador geral é composto por crimes contra o patrimônio uma vez que, apesar das suavizações obtidas pelo INLA, grande parte das ocorrências criminais são contra o patrimônio. O índice contra o patrimônio de 2015 resultou em 48,14 enquanto que contra a vida 1,01. Ainda analisando esta figura, é possível notar o acentuado grau de crimes contra a vida do município de Alvorada, onde em 2014 alcançou o patamar de 1,5.

Por outro lado, a Figura 4.5 mostra a dinâmica dos três índices para alguns municípios anômalos selecionados e comentados na Seção 3.3. Nestes gráficos é possível notar um comportamento mais errático em todas as séries temporais. O ICrime apresenta valores muito menores do que os dos municípios mais relevantes, tendo valores próximos a seis dias. Outra característica que chama a atenção é o fato de que novamente o índice é dominado pelas ocorrências criminais patrimoniais. Para o município de São José do Herval em 2006, por exemplo, é esperado que cada habitante passe 10,72 dias na cadeia para pagar por todos os crimes cometidos, sendo que desse tempo 10,46 seriam apenas referentes aos crimes patrimoniais.

O gráfico mais à direita ilustra os índices dos crimes cometidos contra a vida. Nele notamos que, apesar de o método ter suavizado as estimativas, uma vez que não existem valores nulos nas séries temporais e os saltos são mais amenos do que as informações brutas, existe uma razoável volatilidade nos valores. Em outras palavras, existem casos em que os índices de crimes contra a vida são bem grandes, principalmente quando comparados com os dez municípios mais relevantes do gráfico anterior. Neste gráfico, o município de Gramado dos Loureiros apresentou o valor de 1,92. 

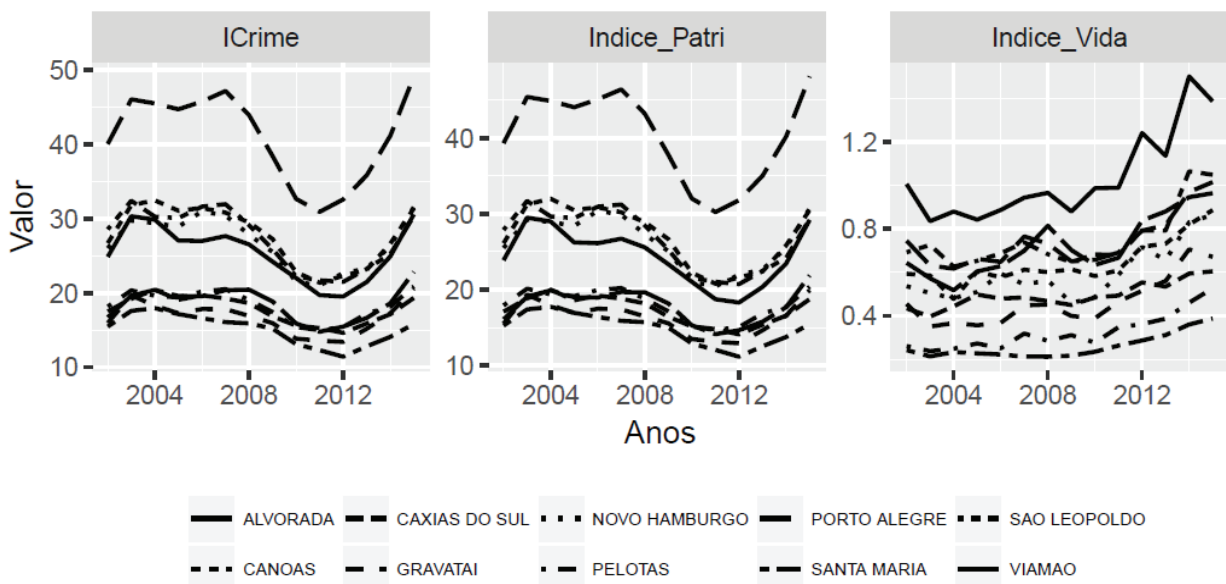

Figura 4.4 - Comparação dos índices para 10 municípios relevantes selecionados. $\mathrm{O}$ painel à esquerda mostra $\mathrm{o}$ ICrime geral, o painel central apresenta $\mathrm{o}$ índice contra o patrimônio e à direita o índice contra a vida.

Fonte: Elaboração própria.

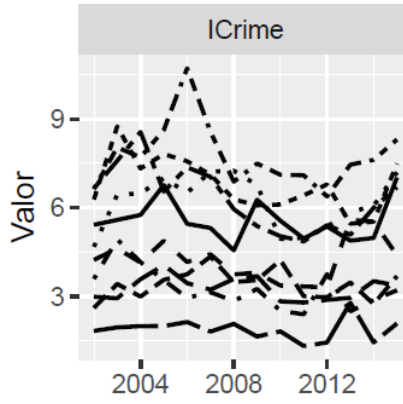

ENTRE RIOS DO SUL
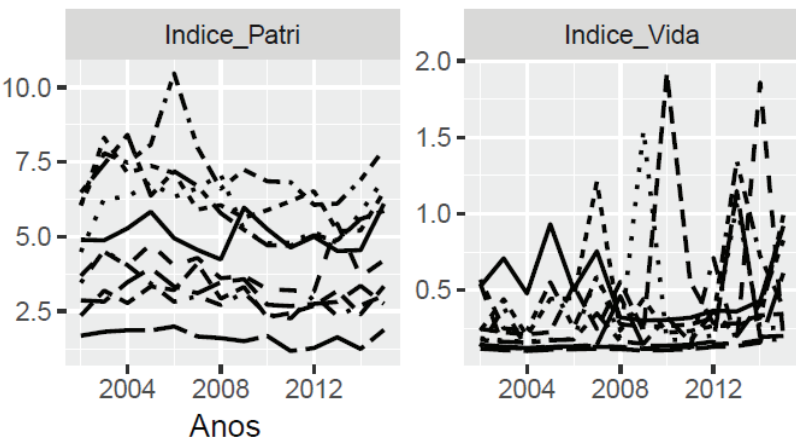

PONTE PRETA

SAO JOSE DO HERVA

Figura 4.5 - Comparação dos índices para 10 municípios atípicos selecionados. O painel à esquerda mostra o ICrime geral, o painel central apresenta o índice contra o patrimônio e à direita o índice contra a vida.

Fonte: Elaboração própria. 
As Tabelas 4.3 e 4.4 apresentam, para alguns anos recentes selecionados, municípios que tiveram os maiores e menores ICrime e Índice de Crime contra a Vida do Rio Grande do Sul. Nestas tabelas podem-se acompanhar os dez maiores municípios em cada ano, bem como os dez menores.

Tabela 4.3 - Rankings municipais do ICrime para anos selecionados: os 10 maiores e os 10 menores municípios

\begin{tabular}{ccccc}
\hline Posição & 2006 & 2009 & 2012 & 2015 \\
\hline $1^{\circ}$ & Xangri-Lá & Cidreira & Xangri-Lá & Porto Alegre \\
$2^{\circ}$ & Porto Alegre & Xangri-Lá & Porto Alegre & Xangri-Lá \\
$3^{\circ}$ & Cidreira & Porto Alegre & Cidreira & Cidreira \\
$4^{\circ}$ & Imbé & Imbé & Imbé & Imbé \\
$5^{\circ}$ & Balneário Pinhal & Arroio do Sal & Tramandaí & Novo Hamburgo \\
$6^{\circ}$ & Tramandaí & Tramandaí & Arroio do Sal & Canoas \\
$7^{\circ}$ & Esteio & Balneário Pinhal & Esteio & Esteio \\
$8^{\circ}$ & Arroio do Sal & Capão da Canoa & Capão da Canoa & Alvorada \\
$9^{\circ}$ & São Leopoldo & Canoas & Novo Hamburgo & São Leopoldo \\
$10^{\circ}$ & Canoas & Esteio & Balneário Pinhal & Tramandaí \\
$486^{\circ}$ & São João da Urtiga & Mariano Moro & Áurea & Ubiretama \\
$487^{\circ}$ & Novo Machado & Santa Maria do Herval & São João da Urtiga & Nova Candelária \\
$488^{\circ}$ & Nova Boa Vista & Ubiretama & Cândido Godói & Santo Expedito do Sul \\
$489^{\circ}$ & Cândido Godoi & São José do Inhacorá & São José do Inhacorá & Canudos do Vale \\
$490^{\circ}$ & Benjamin Constant do Sul & Nova Candelária & Mato Queimado & São João da Urtiga \\
$491^{\circ}$ & Centenário & Cândido Godoí & Nova Candelaria & Morrinhos do Sul \\
$492^{\circ}$ & Nova Candelária & Arroio do Padre & Canudos do Vale & Arroio do Padre \\
$493^{\circ}$ & Novo Xingu & Mato Queimado & Travesseiro & Benjamin Constant do Sul \\
$494^{\circ}$ & Arroio do Padre & Morrinhos do Sul & Arroio do Padre & Novo Xingu \\
$495^{\circ}$ & Cruzaltense & Centenário & Centenário & Mato Queimado \\
$496^{\circ}$ & Mato Queimado & Cruzaltense & Morrinhos do Sul & Centenário \\
\hline & & & &
\end{tabular}

Fonte: Elaboração própria. 
Tabela 4.4- Rankings municipais do índice Criminal contra a vida para anos selecionados: os 10 maiores e os 10 menores municípios

\begin{tabular}{|c|c|c|c|c|}
\hline Posição & 2006 & 2009 & 2012 & 2015 \\
\hline $1^{0}$ & Taquarucu do Sul & Nicolau Vergueiro & Cotiporá & Alvorada \\
\hline $2^{0}$ & Pirapó & Novo Xingu & Vicente Dutra & Vicente Dutra \\
\hline $3^{0}$ & Dezesseis de Novembro & Pouso Novo & Ivorá & Balneário Pinhal \\
\hline $4^{0}$ & Vicente Dutra & Pirapó & Alvorada & São Leopoldo \\
\hline $5^{0}$ & Alvorada & Ciríaco & Viamao & Porto Alegre \\
\hline $6^{0}$ & Itapuca & Dilermando de Aguiar & Alpestre & Esmeralda \\
\hline $7^{0}$ & Vila Flores & Alvorada & Jaquirana & Viamão \\
\hline $8^{0}$ & Dois Lajeados & Miraguaí & São Leopoldo & Entre Rios do Sul \\
\hline $9^{0}$ & Cerro Grande do Sul & Cerro Grande & Porto Alegre & Cidreira \\
\hline $10^{\circ}$ & André da Rocha & Capão da Canoa & Capao da Canoa & Canoas \\
\hline $486^{\circ}$ & Boa Vista do Burica & Augusto Pestana & Nova Candelaria & Nova Candelária \\
\hline $487^{\circ}$ & Westfália & Salvador do Sul & Augusto Pestana & Santo Cristo \\
\hline $488^{\circ}$ & Tuparendi & Doutor Maurício Cardoso & Salvador do Sul & Sao Pedro da Serra \\
\hline $489^{\circ}$ & Ubiretama & Mariano Moro & Doutor Mauricio Cardoso & Antônio Prado \\
\hline $490^{\circ}$ & Nova Candelária & Centenário & Sao Pedro da Serra & Doutor Maurício Cardoso \\
\hline $491^{\circ}$ & Mariano Moro & Sao Pedro da Serra & Antônio Prado & Mariano Moro \\
\hline $492^{\circ}$ & Centenário & Antônio Prado & Mariano Moro & Centenário \\
\hline $493^{\circ}$ & Santo Cristo & Carlos Barbosa & Sananduva & Carlos Barbosa \\
\hline $494^{\circ}$ & Doutor Maurício Cardoso & Westfália & Centenário & Westfália \\
\hline $495^{\circ}$ & Marcelino Ramos & Cândido Godói & Westfália & Marcelino Ramos \\
\hline $496^{\circ}$ & Cândido Godói & Marcelino Ramos & Cândido Godói & Cândido Godói \\
\hline
\end{tabular}

Fonte: Elaboração própria. 
A Tabela 4.3 mostra que, novamente, grande parte dos municípios que apresentam os maiores índices de criminalidade são municípios litorâneos. Em 2015, nota-se que estão presentes Xangri-lá, Cidreira, Imbé e Tramandaí nos dez maiores municípios, enquanto que Porto Alegre é o maior e Novo Hamburgo, Canoas, Esteio, Alvorada e São Leopoldo ocupam, respectivamente, da quinta à nona posição. Neste mesmo ano, municípios menos expressivos são os municípios mais "seguros" como Centenário, Mato Queimado e Novo Xingú. Em relação aos demais anos é possível notar um grau de robustez nas posições municipais. Por exemplo, a capital Porto Alegre está sempre entre as três cidades com maiores índices, Xangri-lá está sempre entre os dois maiores municípios, Imbé está na quarta posição em todos os anos, Esteio está sempre entre a sétima e décima posição, Centenário é um dos municípios com os menores índices estando sempre entre a $491^{a}$ e a última posição, Nova Candelária, Arroio do Padre e Mato Queimado são municípios com os menores índices em todos os anos selecionados.

Analisando a Tabela 4.4, que se refere aos rankings municipais de crimes contra a vida, vê-se que o comportamento dos rankings é mais errático entre os anos. Em 2015, Alvorada, Vicente Dutra, Balneário Pinhal, São Leopoldo e Porto Alegre lideram o ranking, enquanto Cândido Godoi, Marcelino Ramos, Westfalia, Carlos Barbosa e Centenário são as cidades com os menores índices de crime contra a vida. Em termos de comparabilidade inter-anual, é possível notar algumas características que se assemelham ao longo do tempo, mas com menor intensidade do que o ICrime. Por exemplo, o município de Alvorada se mostrou presente com altas taxas criminais vitais em todos os anos sempre ocupando altas posições nos rankings. A capital Porto Alegre e os municípios de São Leopoldo e Viamão se mostraram presentes em 2015 e 2012. Por outro lado, Cândido Godoi e Marcelino Ramos se mostraram sempre na última ou penúltima posição (exceto em 2012, Westfalia foi a penúltima), Mariano Moro é um município com baixas taxas criminais vitais, ocupando sempre entre a $489^{\mathrm{a}}$ e $492^{\mathrm{a}}$ posições e Westfalia e Doutor Maurício Cardoso estão presentes em todos os anos selecionados entre os municípios com menores taxas.

Comparando com a Tabela 3.3, apresentada na Seção 3.3, é imperativo que se note algumas semelhanças, mas sobretudo mudanças substanciais quando se olha o ano de 2015. Apesar de existir um grande indício de que o ICrime possui uma relação intrínseca com o tipo de crime de maior ocorrência (o Furto), que tipicamente apresentam as maiores taxas em 
municípios do litoral norte, foi Porto Alegre que liderou o ICrime em 2015 com um valor de 49,15. No entanto, o efeito do Furto no ICrime neste ano possui uma relevância, uma vez que Xangri-lá, Imbé, Cidreira são cidades que apresentam algumas das maiores taxas de Furto (Tabela 3.3) e maiores ICrime (Tabela 3.3). Com relação aos crimes contra a vida, as diferenças são substanciais, pois o município que lidera o ranking de mais perigoso em termos de crimes vitais é Alvorada, que não está presente nas cinco maiores taxas brutas de latrocínio ou de homicídio. Outra característica importante de se ressaltar é a de que o município de Esmeralda que apresentava a impressionante taxa de 91 homicídios por 100 mil habitantes, liderando o ranking, caiu para a sexta posição de crimes contra a vida. Adicionalmente, cidades que não apresentavam altas posições em termos de taxas brutas de homicídios e latrocínios, apareceram como altamente violentas, como é o caso de Porto Alegre, Vicente Dutra, Viamão e Canoas.

É interessante comparar também os resultados obtidos com o indicador sugerido por Freitas, Cadaval e Gonçalves (2016). Analisando o ano de 2012 da Tabela 4.3, nota-se um padrão de municípios litorâneos no topo da lista e municípios mais atípicos no final da lista. Este padrão não é similar ao resultado desses autores, pois a sua abordagem fez uma padronização prévia entre zero e um das taxas criminais, retirando o efeito da magnitude de cada crime, o que resulta em municípios metropolitanos com menor bem-estar. Ademais, nos municípios com menores índices de criminalidade do trabalho de Freitas, Cadaval e Gonçalves (2016) não existe diferenciação de valor, em que os 29 municípios mais "seguros" apresentam o mesmo valor de índice até a terceira casa decimal. Sendo assim, as diferentes abordagens do presente trabalho se diferenciam consideravelmente de Freitas, Cadaval e Gonçalves (2016) e, consequentemente, geram resultados bem diferentes. A suavização proposta com o presente método tangibiliza o problema de variabilidade sem perder as especificidades regionais.

\section{Considerações Finais}

Este trabalho teve como objetivo fazer um estudo da criminalidade no estado do Rio Grande do Sul e seus municípios e propor um índice geral de criminalidade. Um dos problemas enfrentados é a estimação de ocorrências em municípios com baixa população. O modelo utilizado tenta 
contornar o problema fazendo uso de um recente método de estimação, em que as taxas em localidades específicas foram suavizadas. Outro aspecto importante é o de que os índices criados fazem uso de diversos tipos de crime como roubo, roubo de veículos, furto, furto de veículos, homicídios, latrocínio e extorsão mediante sequestro a fim de tentar mensurar a verdadeira taxa delinquencial de determinada região e ano. Neste sentido, o índice geral não representa somente a usual taxa de homicídio, que é o principal indicador utilizado na literatura da Economia do Crime, mas sim uma combinação de diversos crimes. Adicionalmente, foram construídos dois indicadores adicionais que representam a desagregação contra o patrimônio e contra a vida. Outro aspecto importante é a interpretabilidade do resultado. Uma vez que o índice representa o somatório das estimativas de ocorrências suavizadas com as penas mínimas previstas em lei, ele se propõe a representar o quanto cada habitante de determinada região deveria passar em dias na cadeia, supondo-se que todos os crimes fossem condenados pela pena mínima.

No entanto, apesar de algumas características desejáveis terem sido contempladas, algumas limitações devem ser apontadas. Um dos maiores desafios é o fato de que existe uma disparidade muito grande de frequência entre os diferentes tipos de crimes. O número absoluto de furtos e roubos é significativamente maior do que de outros crimes como homicídio e, mais ainda, latrocínio. Esta característica afeta as estimativas dos índices gerais de criminalidade, o que motivou a sua desagregação em índices contra a vida e contra o patrimônio. É razoável pensar que crimes contra o patrimônio são os que afetam mais significativamente o nosso bem-estar, uma vez que crimes contra a vida são raros de acontecer. Em outras palavras, é mais crível supor que a maioria das pessoas possui receio de perder bens materiais e sofrer um assalto (pois isto é mais frequente) do que sofrer um latrocínio, ${ }^{23}$ por exemplo. Sendo assim, o índice geral refletir, em grande parte, os crimes contra o patrimônio têm justificativa, uma vez que ele busca medir a realização criminal e a sensação de insegurança.

Outra limitação que deve ser apontada é a de que mesmo com o método ter suavizado as estimativas, o problema de magnitude de taxas em regiões pouco populosas continua presente em certo grau. Uma alternativa a ser

${ }^{23}$ Apesar de que o latrocínio possui a maior pena prevista em lei e possui grande apelo emocional, tanto da mídia, quanto do público em geral. 
utilizada seria trabalhar com padronização ${ }^{24}$ ou normalização, ${ }^{25}$ no entanto, em ambas as abordagens a interpretabilidade do indicador se perde uma vez que estas transformações alteram a unidade de medida da variável original. Sendo assim, mesmo que o método INLA não seja trivial, a interpretabilidade do método proposto é simples. Adicionalmente, como possibilidades de extensões, outras estruturas de vizinhança e ponderações poderiam ser testadas.

\section{Referências}

Akaike, H. 1997. "Information theory and an extension of the maximum likelihood principle". 2nd International Symposium on Information Theory, p. 267-281.

Banerjee, S., Carlin, B., Gelfand, A. 2004. "Hierarchical modeling and analysis for spatial data". [S.1.]: Chapman \& Hall/CRC 101.

Beato, F., Claudio, C. 1998. "Determinantes da criminalidade em minas gerais". Revista Brasileira de Ciências Sociais SciELO Brasil 13(37): 74-87.

Besag, J. 1974. "Spatial Interaction and Statistical Analysis of Lattice Systems”. Journal of the LRoyal Statistical Society Series B 36(2): 579-602.

Besag, J., York, J., Mollie, A. 1991. "Bayesian image restoration, with two applications in spatial statistics". Annals of the Institute of Statistical Mathematics 43:1-59.

Bivand, R. S., Pebesma, E., Gómez-Rubio, V. 2008. “Applied Spatial Data Analysis with R”. [S.1.]: Springer.

Blangiardo, M., Cameletti, M. 2015. "Spatial and spatio-temporal Bayesian models with R-INLA”. [S.1.]: John Wiley \& Sons.

Blangiardo, M. et al. 2013. "Spatial and spatio-temporal models with r-inla". Spatial and Spatio-temporal Epidemiology, Elsevier 7: 39-55.

Carvalho, A., Marques Da Silva, G., Junior, G. R., Albuquerque, P. H. M. 2012. “Taxas Bayesianas para o mapeamento de homicídios nos municípios brasileiros”. Cadernos de Saúde Pública 28(7): 1249-1262.

Catelan, D., Lagazio, C., Biggeri, A. 2010. "A hierarchical Bayesian approach to multiple testing in disease mapping". Biometrical Journal 52(6).

Cerqueira, D. et al. 2013. "A singular dinâmica territorial dos homicídios no Brasil nos anos 2000". [S.1.]: Brasil em Desenvolvimento 2013: estado, planejamento e políticas públicas. Instituto de Pesquisa Econômica Aplicada, Capítulo 29.

Cerqueira D., Lobão, W., Carvalho, A. X. 2005. “O jogo dos sete mitos and a miséria da segurança pública no Brasil”. [S.1.]: Instituto de Pesquisa Econômica e Aplicada. Texto para discussão, n 1144.

Cidade, G. V. D. 2012. “A implementação do PRONASCI na região metropolitana de porto alegre: Um estudo sobre o processo e efetividade da federalização das políticas públicas de segurança pública”.

\footnotetext{
${ }^{24}$ A variável $X$ é padronizada quando se constrói uma variável $Z=\frac{X-\mu_{X}}{\sigma_{X}}$.

${ }^{25}$ A variável $X$ é normalizada quando se constrói uma variável $Z=\frac{X-\min _{X}}{\max _{X}-\min _{X}}$.
} 
Clayton, D., Kaldor, J. 1987. "Empirical bayes estimates of age-standardized relative risks for use in disease mapping”. Biometrics, JSTOR, 671-681.

Cortes, R. X. 2014. "Estimando modelos dinâmicos utilizando o INLA para Campos Aleatórios Markovianos Não Gaussianos". [S.1.]: Dissertação de Mestrado. Pós-graduação em Estatística da Universidade Federal de Minas Gerais.

Cortes, R. X. 2016. "Investigação de padrões criminais e de indicadores de segurança para os municípios do Rio Grande do Sul, por meio de técnicas estatísticas multivariadas". [S.1.]: Fundação de Economia e Estatística. Texto para Discussão, no. 143.

Dey, D. K., Chen, M. H., Chang, H. 1997. "Bayesian approach for nonlinear random effects models". Biometrics 53: $1239-1252$.

Freitas, T. A. D., Cadaval, A. F., Gonçalves, G. A. 2016. “A estimação de um índice geral de criminalidade para os municípios do Rio Grande do Sul - IGcrime RS”. [S.l.]: XIX Encontro de Economia da Região Sul.

Gamerman, D., Lopes, H. 2006. "Markov chain Monte Carlo: stochastic simulation for Bayesian inference". [S.1.]: Chapman \& Hall/CRC.

Gelfand, A., Smith, A. 1990. "Sampling-based approaches to calculating marginal densities". Journal of the American statistical association, American Statistical Association 85(410): 398-409.

Gelfand, A. E., Dey, D. K., Chang, H. 1992. "Model determination using predictive distributions, with implementation via sampling-based methods". Bayesian Statistics 4. Proceedings of the Fourth Valencia International Meeting, p. 147-159.

Gelman, A., Rubin, D. 1992. "Inference from Iterative Simulation Using Multiple Sequences" (with discussion), Statistical Science 7: 457-511.

Geman, S., Geman, D. 1984. "Stochastic Relaxation, Gibbs Distributions, and the Bayesian Restoration of Images". IEEE Transactions on Pattern Analysis and Machine Intelligence 6(6): 721-741.

Justus, M. D. S., Kassouf, A. L. 2008. "Estudos Econômicos das Causas da Criminalidade no Brasil: Evidências e Controvérsias". Revista EconomiA 9(2): 343-372.

Kerber, A. O., Pazinato, E. 2016. "Muitas cabeças, muitas sentenças: Uma análise do PRONASCI em Canoas/ RS a partir das representações sociais dos moradores e dos gestores do território de paz". [S.L.]: Multi Ideias.

Khan, T. 2005. "Estatística de Criminalidade: Manual de Interpretação". SSP-SP (Acesso em 20/09/2017).

Disponível em: < http://www.ssp.sp.gov.br/media/documents/ manual interpretacao.pdf $>$.

Knorr-Held, L. 1999. "Bayesian modelling of inseparable space-time variation in disease risk".

Kohavi, R. 1995. "A study of cross-validation and bootstrap for accuracy estimation and model selection". Proceedings of the Fourteenth International Joint Conference on Artificial Intelligence 2(12): 1137-1143.

Laurini, M. P. 2016. "Income estimation using night luminosity: A continuous spatial model”. Spatial Demography, Springer 4(2): 83-115.

Laurini, M. P. 2017. "A spatial error model with continuous random effects and an application to growth convergence". Journal of Geographical Systems, Springer 19(4): 371-398.

Lesage, J. P. 1997. "Bayesian estimation of spatial autoregressive models". International Regional Science Review 20(1-2): 113-129.

Lesage, J. P. 1999. “The theory and practice of spatial econometrics”. [S.1.]: Department of Economics, University of Toledo.

Marshall, R. J. 1991. "Mapping disease and mortality rates using empirical Bayes estimators". Journal of the Royal Statistical Society: Series C 40(2).

Martino, S., Rue, H. 2009. "Implementing approximate Bayesian inference using Integrated Nested Laplace Approximation: A manual for the INLA program". Department of Mathematical Sciences, NTNU, Norway, Citeseer. 
Martins, T. et al. 2012. "Bayesian computing with INLA: new features". Department of Mathematical Sciences, NTNU, Norway.

Monteiro, J. B. 2009. "Indicador de Criminalidade Geral Baseado em Métodos Multivariados e Estatística Espacial para Controle na Segurança Pública do Estado”. [S.1.]: Universidade Federal do Rio Grande do Sul. Monografia do Curso de Estatística.

Pringle, D. G. 1996. "Mapping disease risk estimates based on small numbers: an assessment of empirical Bayes techniques". Economia and Social Review 27(4).

Raftery, A., Lewis, S. 1992. "How Many Iterations in the Gibbs Sampler?” Bayesian Statistics 4: 763-773.

Rue, H., Martino, S., Chopin, N. 2009. “Approximate Bayesian inference for latent Gaussian models by using integrated nested Laplace approximations". Journal of the Royal Statistical Society: Series B (Statistical Methodology), Citeseer 71(2): 319-392.

Ruiz-Cárdenas, R., Krainski, E, Rue, H. 2011. "Direct fitting of dynamic models using integrated nested laplace approximations-inla". Computational Statistics \& Data Analysis, Elsevier.

Saraiva, M. V., Conceicao, O. C., Franca, M. T. A. 2016. "Os determinantes da criminalidade nos municípios gaúchos: evidências de um modelo econométrico espacial”. [S.1.]: XVII Seminário sobre a Economia Mineira. CEDEPLAR: Universidade Federal de Minas Gerais.

Shaw Clifford, R., Mckay, H. 1942. "Juvenile Delinquency in Urban Areas”. [S.1.]: Chicago: University of Chicago Press.

Spiegelhalter, D. et al. 1997. "Bayesian approach for nonlinear random effects models". Biometrics 53: 1239-1252.

Waiselfisz, J. 2014. "Mapa da Violência 2014: Os jovens do Brasil”. [S.1.]: Flacso.

Zuanazzi, P. T., Bartels, M. 2016. "Estimativas para a população flutuante do Litoral Norte do RS". [S.1.]: Porto Alegre: FEE. 